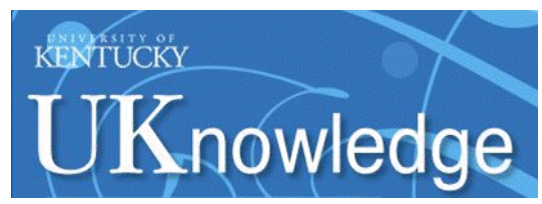

University of Kentucky

UKnowledge

\title{
Rat Hippocampal Responses up to 90 Days After a Single Nanoceria Dose Extends a Hierarchical Oxidative Stress Model for Nanoparticle Toxicity
}

\author{
Sarita S. Hardas \\ University of Kentucky, saritash135@gmail.com \\ Rukhsana Sultana \\ University of Kentucky, rsult2@uky.edu \\ Govind Warrier \\ University of Kentucky \\ Mo Dan \\ University of Kentucky, mo.dan@uky.edu \\ Peng Wu \\ University of Kentucky, peng.wu@uky.edu \\ Follow this and additional works at: https://uknowledge.uky.edu/chemistry_facpub \\ ia next page for additional authors \\ Part of the Chemistry Commons, and the Pharmacy and Pharmaceutical Sciences Commons \\ Right click to open a feedback form in a new tab to let us know how this document benefits you.
}

\section{Repository Citation}

Hardas, Sarita S.; Sultana, Rukhsana; Warrier, Govind; Dan, Mo; Wu, Peng; Grulke, Eric A.; Tseng, Michael T.; Unrine, Jason M.; Graham, Uschi M.; Yokel, Robert A.; and Butterfield, D. Allan, "Rat Hippocampal Responses up to 90 Days After a Single Nanoceria Dose Extends a Hierarchical Oxidative Stress Model for Nanoparticle Toxicity" (2014). Chemistry Faculty Publications. 186.

https://uknowledge.uky.edu/chemistry_facpub/186

This Article is brought to you for free and open access by the Chemistry at UKnowledge. It has been accepted for inclusion in Chemistry Faculty Publications by an authorized administrator of UKnowledge. For more information, please contact UKnowledge@lsv.uky.edu. 


\title{
Rat Hippocampal Responses up to 90 Days After a Single Nanoceria Dose Extends a Hierarchical Oxidative Stress Model for Nanoparticle Toxicity
}

\author{
Digital Object Identifier (DOI) \\ https://doi.org/10.3109/17435390.2013.868059
}

\section{Notes/Citation Information}

Published in Nanotoxicology, v. 8, suppl. 1.

This is an Accepted Manuscript version of the following article, accepted for publication in Nanotoxicology. Hardas, S. S., Sultana, R., Warrier, G., Dan, M., Wu, P., Grulke, E. A., Tseng, M. T., Unrine, J. M., Graham, U. M., Yokel, R. A., \& Butterfield, D. A. (2014). Rat hippocampal responses up to 90 days after a single nanoceria dose extends a hierarchical oxidative stress model for nanoparticle toxicity. Nanotoxicology, 8(sup1), 155-166. https://doi.org/10.3109/17435390.2013.868059

It is deposited under the terms of the Creative Commons Attribution-NonCommercial-NoDerivatives License (https://creativecommons.org/licenses/by-nc-nd/4.0/), which permits non-commercial re-use, distribution, and reproduction in any medium, provided the original work is properly cited, and is not altered, transformed, or built upon in any way.

\section{Authors}

Sarita S. Hardas, Rukhsana Sultana, Govind Warrier, Mo Dan, Peng Wu, Eric A. Grulke, Michael T. Tseng, Jason M. Unrine, Uschi M. Graham, Robert A. Yokel, and D. Allan Butterfield 


\section{Rat hippocampal responses up to 90 days after a single nanoceria dose extends a hierarchical oxidative stress model for nanoparticle toxicity}

Sarita S. Hardas ${ }^{a}$, Rukhsana Sultana $^{a}$, Govind Warrier ${ }^{a}$, Mo Dan ${ }^{b}$, Peng Wu ${ }^{c}$, Eric A. Grulke $^{c}$, Michael T. Tseng ${ }^{d}$, Jason M. Unrine ${ }^{e}$, Uschi M. Graham ${ }^{f}$, Robert A. Yokel ${ }^{b, g}$ and D. Allan Butterfield ${ }^{a, h} *$

Sarita S. Hardas: a Department of Chemistry, University of Kentucky, Lexington, Kentucky 40506-0055.Email: sarita.hardas@uky.edu, saritash135@gmail.com

Rukhsana Sultana: ${ }^{a}$ Department of Chemistry, University of Kentucky, Lexington, Kentucky 40506-0055. Email: rsult2@uky.edu

Govind Warrier: a Department of Chemistry, University of Kentucky, Lexington, Kentucky 40506-0055. Email: govind.warrier@uky.edu

Mo Dan: ${ }^{b}$ Department of Pharmaceutical Sciences, University of Kentucky Academic Medical Center, University of Kentucky, Lexington, Kentucky 40536-0596. Current address: National Center for Safety Evaluation of Drugs, National Institutes for Food and Drug Control, Beijing, 100176, China, Email: danmo@nicpbp.org.cn

Peng Wu: ${ }^{\mathrm{c}}$ Chemical and Materials Engineering Department, University of Kentucky, Lexington, Kentucky 40506-0503. Email: peng.wu@uky.edu

Eric A. Grulke: ${ }^{\mathrm{c}}$ Chemical and Materials Engineering Department, University of Kentucky, Lexington, Kentucky 40506-0503. Email: eric.grulke@uky.edu

Michael T. Tseng: ${ }^{\mathrm{d}}$ Department of Anatomical Sciences \& Neurobiology, University of Louisville, Louisville, Kentucky 40202. Email: mttsen01@louisville.edu

Jason M. Unrine: ${ }^{\circledR}$ Department of Plant and Soil Sciences, University of Kentucky, Lexington, Kentucky 40546-0091. Email: jason.unrine@uky.edu

Uschi M. Graham: ${ }^{\mathrm{f}}$ Center for Applied Energy Research, University of Kentucky, Lexington, Kentucky 40511. Email: uschi.graham@uky.edu

Robert A. Yokel: ${ }^{b}$ Department of Pharmaceutical Sciences, University of Kentucky Academic Medical Center, University of Kentucky, Lexington, Kentucky $40536-0596,{ }^{\mathrm{g}}$ Graduate Center 
for Toxicology, University of Kentucky Academic Medical Center, Lexington, Kentucky 405069983. Email: ryokel@email.uky.edu

D. Allan Butterfield: ${ }^{a}$ Department of Chemistry, University of Kentucky, Lexington, Kentucky 40506-0055, h Center of Membrane Sciences, University of Kentucky, Lexington, Kentucky 40506-0059. Email: dabcns@uky.edu

\section{*Corresponding author:}

D. Allan Butterfield, Ph.D.

Department of Chemistry,

University of Kentucky,

Lexington,

Kentucky 40506-0055.

Phone: 859-257-3184

Fax: 859-323-1069

Email: dabcns@uky.edu

Running Head: New insights into nanoceria in vivo brain toxicity.

Key words: engineered nanomaterial, hierarchical model, hippocampus, nanoceria, oxidative stress, 


\section{Abbreviations:}

3NT protein bound 3-nitrotyrosine

ARE antioxidant response element

Ce cerium

Cat catalase

EELS electron energy loss spectroscopy

ENM engineered nanomaterial

GPx glutathione peroxidase

GR glutathione reductase

GSH reduced glutathione

GSSG oxidized glutathione

$\mathrm{H}_{2} \mathrm{O}_{2} \quad$ hydrogen peroxide

HOS hierarchical oxidative stress model

HO-1 heme oxygenase -1

Hsp70 heat shock protein 70

$\mathrm{LDH}$ lactate dehydrogenase

MAPK mitogen-activated protein kinase

Nrf-2 nuclear factor-2

NF-кB nuclear factor kappa B

PC protein carbonyl

OPT o-phthaldehyde 
ROS reactive oxygen species

RNS reactive nitrogen species

SOD superoxide dismutase

TEM transmission electron microscopy 


\begin{abstract}
Ceria engineered nanomaterials (ENMs) have very promising commercial and therapeutic applications. Few reports address the effects of nanoceria in intact mammals, let alone long term exposure. This knowledge is essential to understand potential therapeutic applications of nanoceria in relation to its hazard assessment. The current study elucidates oxidative stress responses in the rat hippocampus 1 and $20 \mathrm{~h}$, and 1, 7, 30, and $90 \mathrm{~d}$ following a single systemic infusion of $30 \mathrm{~nm}$ nanoceria. The results are incorporated into a previously described hierarchical oxidative stress (HOS) model. During the 1-20 h period, increases of the GSSG: GSH ratio and cytoprotective phase-II antioxidants were observed. During the 1-7 d period, cytoprotective phase-II antioxidants activities were inhibited with concomitant elevation of protein carbonyl (PC), 3-nitrotyrosine (3NT), heme oxygenase-1 (HO-1), cytokine IL-1 $\beta$ and the autophagy marker LC-3AB. At 30 d post ceria infusion, oxidative stress had its major impact. Phase-II enzyme activities were inhibited; concurrently PC, 3NT, HO-1, and Hsp70 levels were elevated along with augmentation of IL-1 $\beta$, pro-apoptotic pro-caspase-3, and LC-3AB levels. This progress of escalating oxidative stress was reversed at $90 \mathrm{~d}$ when phase-II enzyme levels and activities were restored to normal levels, PC and 3NT levels were reduced to baseline, cytokine and pro-caspase-3 levels were suppressed, and cellular redox balance was restored in the rat hippocampus. This study demonstrates that a single administration of nanoceria induced oxidative stress that escalates to 30 days then terminates, in spite of the previously reported continued presence of nanoceria in peripheral organs. These results for the first time confirm in vivo the HOS model of response to ENM previously posited based on in vitro studies and extends this prior hierarchical oxidative stress model that described three tiers to a 4 th tier, characterized by resolution of the oxidative stress and return to normal conditions.
\end{abstract}




\section{Introduction}

Engineered nanomaterials (ENMs) can be synthesized with different shapes, sizes, composition, surface coatings, and surface morphology. With versatile physical, chemical and magnetic properties, ENMs have ever-growing applications in electronics, scientific instruments, sport equipments, cosmetics, fabrics and their treatments, and as diesel fuel additives, automotive components, drug delivery systems, and pharmaceuticals (Buzea et al., 2007, Sahu et al., 2013, Das et al., 2012). Many of these applications are becoming an integral part of our lives. Some ENMs produce intended outcomes like drug and gene delivery and some produce unintended consequences through occupational and environmental exposures. Although for many years researchers were aware of the detrimental health effects of exposure to various ambient ultrafine particles, it is only recently that scientists are addressing potential health problems of ENM exposure (Buzea et al., 2007, Yokel et al., 2011). A concern is that insufficient understanding of ENM toxicity could lead to human health problems and decreased public acceptance.

Ceria (a.k.a. cerium oxide) ENM has numerous current and potential commercial applications (Hardas et al., 2010). In the integrated circuit manufacturing industry (Feng et al., 2006), ceria is popularly used as an abrasive due to its abrasiveness. The redox activity of ceria impel its applications as an oxygen sensor (Molin et al., 2008) and oxygen storage promoters (Yuan et al., 2009); diesel fuel catalyst facilitating conversion of carbon monoxide to carbon dioxide and increasing fuel combustion efficiency (Cassee et al., 2011, Park et al., 2007), and as a catalyst for $\mathrm{H}_{2}$ production from fuel cells (Yuan et al., 2009). Also due to its redox active nature, ceria reportedly can serve as a reactive oxygen species (ROS) scavenger in biological systems (Celardo et al., 2011a) where Ce III exhibits antioxidant SOD-like activity (Das et al., 2007, Karakoti et al., 2009a, Korsvik et al., 2007) while Ce IV has catalase-like behavior (Celardo et 
al., 2011a, Celardo et al., 2011b, Heckert et al., 2008, Karakoti et al., 2009a, Pirmohamed et al., 2010). Multiple in vitro studies have documented the ability of ceria to reduce levels of $\mathrm{H}_{2} \mathrm{O}_{2}$, superoxide radical, i-NOS, NF- $\kappa \mathrm{B}, \mathrm{TNF}-\alpha$, interleukins, and other ROS endpoints (Celardo et al., 2011b), to protect against $\mathrm{H}_{2} \mathrm{O}_{2}$ induced apoptosis (Chen et al., 2013), and to favorably modulate cell differentiation and dopamine production (Ciofani et al., 2013). These mechanisms may explain nanoceria's demonstrated therapeutic potential for, diabetic cardiomyopathy, diesel exhaust- and cigarette smoke-induced oxidative stress, radiation therapy side effects, retinal degradation, cancer, stroke and neurodegenerative disorders (Babu et al., 2010, Celardo et al., 2011b, Chen et al., 2006, Colon et al., 2010, D'Angelo et al., 2009, Das et al., 2007, Estevez et al., 2011, Hirst et al., 2009, Niu et al., 2011, Xia et al., 2008). Noteworthy, most of these studies were conducted in in vitro models of oxidative stress.

Along with evidence of the antioxidant behavior of ceria, evidence of ceria-induced toxicity also has been accumulating, which makes the true biological behavior of ceria of concern. Ceria treatments have induced levels of lactate dehydrogenase and the lipid peroxidation productmalonaldehyde, which were associated with decreased cell viability. Ceria decreased reduced glutathione levels and DNA content (Auffan et al., 2009, Brunner et al., 2006, Lin et al., 2006, Park et al., 2008). Co-exposure of nanoceria with diesel exhaust increased cytotoxicity and altered cellular morphology, compared to that seen with diesel exhaust alone (Steiner et al., 2012). Again noteworthy, most of the reports of ceria-induced toxicity were conducted in nonoxidative stress-stimulated cells. Exposure to ceria was deleterious to Synechocystis PCC6803 and Anabaena CPB4337 (cyanobactreria), Pseudokirchneriella subcapitata (green algae), E. coli, Daphnia magna, and C. elegans, decreasing growth, fertility, and survival and increasing 
accumulation of lipofuscin and susceptibility to oxidative stress (Rodea-Palomares et al., 2011, Roh et al., 2010, Thill et al., 2006, Van H et al., 2009, Zeyons et al., 2009).

Due to the variety of its commercial applications, nanoceria was selected for toxicity evaluation by the NIEHS (NIEHS, 2006) and the OECD Environment Directorate (OECD, 2008, OECD, 2010). Long-term effects of nanoceria in intact animals have not been addressed adequately, which is required for the safe use of nanoceria in medical applications and to understand the effects of unintended exposures (Yokel et al., 2012, Yokel et al., 2009). Some studies addressed the effects of ceria ENM in the intact mammal over a short time, finding granulomatous inflammation after pulmonary instillation and inhalation in rats (Cho et al., 2010, Srinivas et al., 2011), reduced myocardial oxidative stress in transgenic mice that displayed ischemic cardiomyopathy (Niu et al., 2007), reduced retinal vascular lesions after intravitreal injections in mice (Zhou et al., 2011), mitigated endometriosis lesions that were induced in mice and inhibited angiogenesis (Chaudhury et al., 2013), pulmonary inflammation and alveolar macrophage functional changes in rats (Ma et al., 2011) and increased oxidative stress in rat brain and liver (Hardas et al., 2012, Tseng et al., 2012). Recently some reviews have focused on the need for in vivo studies examining nanoceria's biokinetics and long-term toxicity (Cassee et al., 2011, Celardo et al., 2011b, Yokel et al., 2011). Taking the first initiative, we explored the long term fate of ceria ENM in an intact animal (Yokel et al., 2012) and found that ceria affects protein carbonyl (PC) levels in a time-dependent manner. In liver, PC levels were increased after 1, 7 and $30 \mathrm{~d}$, and decreased in the spleen at the same time points. In both organs, PC levels were significantly reduced $90 \mathrm{~d}$ after ceria infusion, in spite of the continuous presence of nanoceria (Yokel et al., 2012). Two other independent studies also reported the long-term effects of singlelocalized injection of ceria ENM into the retina, where most of nano-ceria was retained even up 
to $120 \mathrm{~d}$. One of these studies showed no cytotoxicity in rat retina $120 \mathrm{~d}$ after a single injection of nanoceria (Wong et al., 2013). In the second study tubby mice-retinal structure was preserved up to $49 \mathrm{~d}$ and later gradual loss occurred after $80 \mathrm{~d}$, although the structural and functional improvement remained significantly different than untreated or saline treated (Cai et al., 2012). This present study is a part of our earlier initiative and the first report addressing the effects of nanoceria on brain up to 90 days after its peripheral administration.

As pointed out by Xia et al. (Xia et al., 2008), biological systems generally are able to integrate multiple pathways of toxicity into a limited number of pathological outcomes, including inflammation, apoptosis, necrosis, fibrosis, hypertrophy, metaplasia and carcinogenesis. The potential biological toxicity of nanomaterials lies in their much larger surface area-to-volume ratio and therefore an increased number of atoms available for surface interaction compared to bulk materials (Nel et al., 2006, Xia et al., 2009). One of the main resultant events of nanomaterial-biological interaction is generation of reactive oxygen species and oxidative stress (Buzea et al., 2007, Nel et al., 2006, Xia et al., 2008, Xia et al., 2009). Increased oxidative stress levels can cause various detrimental cellular effects such as lipid peroxidation, protein alteration, DNA damage, and disruption of cellular signaling, inflammation, modulation of gene transcription, apoptosis and necrosis.

The hierarchical oxidative stress (HOS) model (Nel et al., 2006), proposed a three-tiered, timedependent cellular response to ENMs that involved low levels of oxidative stress (Tier 1) leading to induction of antioxidant and protective responses mediated by the Nrf-2-ARE-signaling pathway, which modulates Phase-II gene transcription (Chia et al., 2010, Lee et al., 2008, Li et al., 2004, Speciale et al., 2011, Xiao et al., 2003). At a higher level of oxidative stress (Tier 2), the cytoprotective properties transcend to pro-inflammatory responses that depend on ROS- 
mediated induction of redox-sensitive MAPK and NF-KB cascades (Xiao et al., 2003). At the highest level of oxidative stress (Tier 3), a perturbation of mitochondrial inner membrane electron transfer and the open/closed status of the mitochondrial permeability transition pore can lead to cellular apoptosis and cytotoxicity. Using this HOS paradigm, previous studies have investigated an interlinked range of cellular responses to ambient ultrafine particles in animal disease models (Gong et al. 2007; Araujo et al. 2008) and to some ENMs, including ceria, in cell culture models (Xia et al. 2008). The HOS model can be used as a predictive scientific platform to access ENM biological toxicity (Nel et al., 2006). However, this model, and indeed most studies of the effects of ENM, has been developed based on in vitro studies.

According to the HOS model (Nel et al., 2006), Tier-1 comprises induction of phase-II antioxidant enzyme defense response, evoked by elevation of the oxidize glutathione to reduce glutathione (GSSG: GSH) ratio and consequent activation of the Nrf-2 signaling pathway. This pathway regulates transcription of phase-II enzymes like glutathione peroxidase (GPx), glutathione reductase (GR), catalase (Cat), super oxide dismutase (SOD) and heme oxygenase-1 (HO-1) through the antioxidant response element-ARE . Therefore, as representative markers of Tier 1 response we measured levels and activities of GPx, GR, catalase and SOD and levels of HO-1. Levels of PC and 3-nitrotyrosine (3NT) give a global estimate of oxidative modification and damage to cellular proteins by means of ROS and RNS (Beal, 2002, Dalle-Donne et al., 2003, Hardas et al., 2010) and thus measured for all the time points. An increase in PC or 3NT level will be an indirect measure of failed antioxidant defense response. If oxidative stress remained high even after activation of Tier 1 antioxidant response then, the pro-inflammatory Tier 2 response will be activated through ROS-mediated induction of redox-sensitive MAPK and NF-KB cascades. As a representative marker of Tier 2 response, we measured levels of 
inflammatory cytokines IL- $1 \beta$ and TNF- $\alpha$. The escalated unhampered oxidative stress may further lead to cellular apoptosis and cytotoxicity, i.e., Tier 3 response. Estimation of levels of pro-caspase-3, which is a precursor for caspase-3, the final executioner of cellular apoptosis, served as a marker for activation of Tier 3 response. In addition to these markers, levels of heat shock family protein Hsp70 and autophagy marker LC-3AB were measured at all time points.

Nanoceria is proposed as a therapeutic agent (Cai et al., 2012, Celardo et al., 2011b, Chaudhury et al., 2013, Ciofani et al., 2013, Karakoti et al., 2009b, Karakoti et al., 2010, Wong et al., 2013), and thus the effects of its long term exposure need investigation. In the present study, we build upon our prior investigations of the effects of nanoceria over short- and medium-periods in terms of brain oxidative stress and other endpoints (Hardas et al., 2010, Hardas et al., 2012, Yokel et al., 2009) to determine if the HOS model extends to in vivo paradigms and to determine if the effects of even longer term exposure follow this model. To evaluate the oxidative stress effects of systemic administration of nanoceria in a time-dependent manner, $30 \mathrm{~nm}$ ceria was administered intravenously in rats. After its infusion, rat hippocampal samples were harvested 1 and $20 \mathrm{~h}$, and 1, 7,30 and $90 \mathrm{~d}$ later, and subjected to selected biochemical assays to assess the HOS model. The study reveals that the HOS model is valid in vivo through Tier 3, but biopersistence of ceria leads to a new tier (Tier 4) in which oxidative stress markers return to normalcy. The results are discussed with respect to the potential use of nanoceria in therapeutic settings.

\section{Materials and Methods}

\subsection{Nanomaterial synthesis and characterization}


Thirty nm nominal diameter citrate-capped nanoceria were synthesized and extensively characterized in house, as described (Dan et al., 2012, Yokel et al., 2013). The nanoceria were cubic (Figure 1) with a BET surface area of $15 \mathrm{~m}^{2} / \mathrm{kg}$. The average (and S.D. diameter) of the primary particles determined by TEM was $31.2(17.1) \mathrm{nm}$. When dispersed in water a bimodal distribution was seen, with an average size at $41 \mathrm{~nm}$ (representing 100\% of the number and 36\% of the volume of the nanoceria) and $273 \mathrm{~nm}$ (representing the remaining 64\%). A TEM image of the particles and results of dynamic light scattering determination have been reported (Yokel et al., 2012, Yokel et al., 2013). The zeta potential of $-56 \pm 8 \mathrm{mV}$ at $\mathrm{pH} \sim 7.3$, and $\sim 18 \%$ citrate surface coated. It was washed and had a free Ce content of $<<1 \%$. It was prepared as a $\sim 5 \%$ dispersion in water for intravenous infusion (Yokel et al., 2013). Prior to and 90 days following administration, the nanoceria was analyzed using electron energy loss spectroscopy (EELS) to determine its M4/M5 ratio as a measure of its original oxidative signature EELS measurements were performed using the 2 Angstrom probe, an alpha of $20 \mathrm{mrad}$, and a beta of $6 \mathrm{mrad}$, to estimate the Ce(III) versus Ce IV oxidation states from the cerium M4 ( 900 eV) and M5 ( 883 $\mathrm{eV})$ edges and M4/M5 ratio.

\subsection{Animals}

This study reports results from 66 male Sprague Dawley rats, weighing $323 \pm 36 \mathrm{~g}$ (mean $\pm \mathrm{SD}$ ) ( 70 days old). The rats were obtained from Harlan, Indianapolis, IN. They were housed individually throughout the study in the University of Kentucky Division of Laboratory Animal Resources facility under a $12: 12 \mathrm{~h}$ light: dark cycle at $70 \pm 8^{\circ} \mathrm{F}$ and 30 to $70 \%$ humidity. The rats had free access to 2018 Harlan diet and reverse osmosis water. Animal work was approved by the University of Kentucky Institutional Animal Care and Use Committee. The research was conducted in accordance with the Guiding Principles in the Use of Animals in Toxicology 
(http://www.toxicology.org/ai/air/air6.asp). Rats were prepared for i.v. ceria (or water, the ENM vehicle) and $1.8 \%$ sodium chloride (saline) infusion by surgical implantation of cannula into each femoral vein, that terminated in the vena cava. A day or two later the nanoceria (or vehicle) was infused. The dose of nanoceria administered to the rats as a $1 \mathrm{~h}$ infusion was found to be 87 $\mathrm{mg}$ ceria (70 $\mathrm{mg}$ cerium) $/ \mathrm{kg}$, determined by ICP-MS analysis of the dosing dispersion. Rats tolerated the ceria infusion well. Daily cage-side observations revealed no adverse effects (Yokel et al., 2012). There were 5 controls and 5 ceria-treated rats in the 1 and $20 \mathrm{~h}$ groups, 3 controls and 3 treated rats in each of the 1 and 7 day groups, 10 controls and 11 treated rats in the 30 day group, and 6 controls and 7 treated rats terminated 90 days after the single nanoceria administration. To determine ceria levels, brain, liver and venous blood samples were collected when the rats were terminated.

\subsection{Cerium quantification}

Tissue and blood samples were microwave digested in digestion vessels by nitric acid and hydrogen peroxide. The samples were diluted, terbium was added as an internal standard, and analyzed compared to cerium standards by ICP-MS. The methods are described in the Supplementary Information of (Yokel et al., 2013). Samples from control rats that did not receive nanoceria, acid blanks (digestion tubes with no tissue sample but otherwise processed identically), and analysis of duplicate samples and a duplicate sample spiked with a known amount of cerium included with every 20 samples were concurrently processed. The cerium concentration in blanks and $>80 \%$ of the samples from the control rats was below the instrument detection limit (0.02 to $0.03 \mu \mathrm{g} / \mathrm{l})$ (Yokel et al., 2012).

\subsection{Biochemical assays for oxidative stress assessment}


Sample preparations for all of the biochemical assays were carried out as previously described (Hardas et al., 2010, Hardas et al., 2012) unless described otherwise. A small portion of unhomogenized frozen hippocampal tissue from each rat was saved for GSH assay. The remaining hippocampal sample from each rat was thawed and homogenized using a manual Wheaton glass homogenizer in Media $1(300-500 \mu \mathrm{L})$ buffer containing: $0.32 \mathrm{M}$ sucrose, $0.10 \mathrm{mM}$ Tris- $\mathrm{HCl}$, $0.10 \mathrm{mM} \mathrm{MgCl} 2,0.08 \mathrm{mM}$ EDTA, $10 \mu \mathrm{g} / \mathrm{ml}$ leupeptin, $0.5 \mu \mathrm{g} / \mathrm{ml}$ pepstatin, $11.5 \mu \mathrm{g} / \mathrm{ml}$ aprotinin and PMSF $40 \mu \mathrm{g} / \mathrm{ml} ; \mathrm{pH}$ 8.0. After sample homogenization, protein concentration was determined by the Pierce bicinchoninic acid (BCA) assay.

\subsubsection{The oxidize: reduce glutathione (GSSG: GSH) ratio}

GSH and GSSG levels were measured simultaneously in un-treated tissue using the Hissin and Hiff fluorescence spectroscopic method (Hissin et al., 1976). A small amount (in mgs) of freshly thawed hippocampal tissue was rapidly weighed, homogenized with metaphosphoric acid (25\%) 1:4 w/v and sodium phosphate $(0.1 \mathrm{M})$ - ethylenediaminetetraacetic acid $(0.005 \mathrm{M})$ buffer $(\mathrm{pH}$ 8) $1: 15 \mathrm{w} / \mathrm{v}$ and then centrifuged. For GSH levels, an aliquot of supernatant was further diluted with phosphate buffer and then incubated with OPT, before determination of fluorescence ( $\lambda_{\mathrm{ex}}$ $350 \mathrm{~nm}$ and $\lambda_{\mathrm{em}} 420 \mathrm{~nm}$ ). For GSSG levels equal volumes of supernatant and N-ethylmaleimide $(0.04 \mathrm{M})$ were incubated for $30 \mathrm{~min}$ and then diluted with sodium hydroxide $(0.1 \mathrm{~N})$, before assaying with OPT. The GSSG: GSH ratio for each sample was calculated by comparing the fluorescence values from each assay to their respective calibration curves. The final values were expressed as $\%$ of mean \pm SEM of treated vs. control samples.

\subsubsection{PC and 3NT levels}


Global levels of the modified protein markers, PC and 3NT were measured employing the slot blot technique (Hardas et al., 2010, Sultana et al., 2008). For measurement of PC levels, each homogenized hippocampal sample $(5 \mu \mathrm{L})$ was derivatized at room temperature by incubation with $5 \mu \mathrm{L}$ of $12 \%$ SDS and $10 \mu \mathrm{L}$ of $10 \mathrm{mM} \mathrm{2,} \mathrm{4-dinitrophenylhydrazine} \mathrm{solution} \mathrm{in} 2 \mathrm{~N} \mathrm{HCl}$ for $20 \mathrm{~min}$. After $20 \mathrm{~min}$ the sample was neutralized by adding $7.5 \mu \mathrm{L}$ of neutralization buffer supplied with the OxyBlot Protein Oxidation Detection Kit (Chemicon International, Millipore, Temecula, CA). Further, a derivatized sample was diluted with phosphate saline buffer (10 mM, $\mathrm{pH} 8$ with $0.88 \% \mathrm{NaCl}$ ) to obtain a final concentration of $1 \mu \mathrm{g} / \mathrm{ml}$. A $250 \mu \mathrm{L}$ aliquot from each diluted sample was loaded in duplicate onto a nitrocellulose membrane under vacuum pressure using a BioRad slot blot apparatus (BioRad, Hercules, CA). The resultant nitrocellulose membrane was incubated with anti-PC rabbit antibody (5: 10,000, Chemicon International, Millipore, Temecula, CA) and subsequently with anti-rabbit alkaline phosphatase secondary antibody (2.5: 10,000, Sigma Aldrich, St. Louis, MO). For 3NT levels each homogenized hippocampal sample ( $5 \mu \mathrm{L}$ ) was incubated at RT with $5 \mu \mathrm{L}$ of $12 \%$ SDS and $10 \mu \mathrm{L}$ of Laemmli buffer ( $0.125 \mathrm{M}$ Tris $\mathrm{pH} 6.8,4 \% \mathrm{v} / \mathrm{v}$ SDS, $20 \% \mathrm{v} / \mathrm{v}$ glycerol) for $20 \mathrm{~min}$ followed by incubation with anti-3NT rabbit antibody (8: 10,000, Sigma Aldrich, St. Louis, MO) and subsequently with anti-rabbit alkaline phosphatase secondary antibody (2.5: 10,000, Sigma Aldrich, St. Louis, MO). Protein-antibody conjugates were detected using an enhanced colorimetric method (Sultana et al., 2008).

\subsubsection{Antioxidant, HSP, and cytokine protein levels}

The levels of phase-II antioxidant proteins GR, GPx, manganese-SOD, and Cat, heat shock proteins HO- 1 and Hsp70, cytokines TNF- $\alpha$ and IL-1 $\beta$, apoptosis marker pro-caspase-3, and autophagy marker LC-3AB, were measured using immunoblotting, i.e., Western blot techniques 
as described (Hardas et al., 2010, Sultana et al., 2008). In brief, $75 \mu \mathrm{g}$ protein from each homogenized hippocampal sample was loaded and separated on SDS-PAGE alongside its respective control. The separated proteins were transferred from polyacrylamide gels to nitrocellulose membranes. The resultant nitrocellulose membranes with protein bound to them were probed separately with primary antibodies raised against specific proteins; polyclonal GR (Abcam, Cambridge, MA), monoclonal GPx (Epitomics, Burlingame, CA), monoclonal manganese-SOD (Epitomics, Burlingame, CA), polyclonal Cat (Epitomics, Burlingame, CA), monoclonal HO-1 (Epitomics, Burlingame, CA), polyclonal Hsp70 (Cell signaling, Boston, MA), polyclonal TNF- $\alpha$ (Abcam, Cambridge, MA), polyclonal IL-1 $\beta$ (Novus Biologicals, Littleton, CO), polyclonal pro-caspase-3 (Calbiochem, EMD Millipore, Billerica, MA), and monoclonal LC3AB (Epitomics, Burlingame, CA), each with 1:1000 dilution. Subsequently each membrane was incubated with a secondary antibody raised against IgG antibody (2.5: 10,000, Sigma Aldrich, St. Louis, MO). Actin was used as a loading control for each protein band. The intensities of protein-antibody conjugates were detected and used for comparison.

\subsubsection{Antioxidant enzyme activities}

The activities of GPx, GR, SOD and Cat antioxidant enzymes were determined using ready-touse specific enzyme assay kits from Cayman Chemical Company (Ann Arbor, MI), according to the manufacturer's directions as described previously (Hardas et al., 2010). Briefly, 10-20 $\mu \mathrm{g}$ of homogenized sample was loaded along with standards provided on a 96-well plate and mixed with the assay buffer provided in the kit. Along with other particular assay related specific reagents, reaction initiator was added to the mixture, such as cumene hydroperoxide for the GPx assay, NADPH for the GR assay, hydrogen peroxide for the Cat assay, and xanthine oxidase for 
the SOD assay. The change in absorbance of the substrate, monitored spectrophometrically, was correlated with the change in concentration of the substrate and the enzyme activity.

\subsection{Data and statistical analysis}

Grubb's test was used to identify outliers in the results from biochemical assays performed for oxidative stress assessment. Hippocampal samples obtained from rats that received saline in both cannulae were used as controls. As described in the Animals section, each time point had its respective control rats. The histograms in the figures are percent of control calculated from ceriatreated samples normalized to their respective time point controls and expressed as $\%$ control mean \pm SEM. Statistical difference was estimated using Students unpaired t-test comparing percent of treated to control values, accepted at $* \mathrm{p}<0.05, \xi \mathrm{p}<0.01$ and $\Theta \mathrm{p}<0.001$.

\section{Results}

\subsection{Ceria concentration in selected sites}

The nanoceria (Figure 1) were rapidly cleared from circulating blood. One site of its accumulation was the liver. Very little ceria was in the brain, much of which could be accounted for by the blood within the vessels perfusing the brain (Table 1). Blood cerium rose sharply in the rats terminated 90 days after nanoceria administration. This may be due to the partial dissolution of nanoceria particles observed in the liver at that time (unpublished findings) and the very low rate of cerium excretion (unpublished findings) consistent with the long half-life of cerium in mammals, assumed to be 3500 days (Ishigure, 1999).

\subsection{EELS Results.}


Since liver accumulated nanoceria while brain did not, EELS data were collected on nanoceria in liver 90 days after nanoceria administration. The EELS results showed 90-day nanoceria in the liver, similar to as-prepared nanoceria, to have a decreased oxygen vacancy and enhanced Ce III at its outer rim (surface layer), while the central (core) region of the particles are in the Ce IV state ( $\sim$ stoichiometric $\mathrm{CeO}_{2}$ ). This enriched Ce III effect at the surface was observed in the EELS spectrum as the height of the narrow intense peaks at the cerium M5 and M4 edges ( $\sim 883$ and $900 \mathrm{eV}$ ) with intensity of M5 greater than that of M4. Two representative EELS spectra from the exterior surface and core zone of the ceria show the enrichment of Ce III at the particle rim (surface layer) (Graham et al., 2013) (Figure 2).

\subsection{Oxidative Stress Indices}

\subsubsection{The GSSG: GSH ratio, an indicator of oxidative stress}

GSH, an important endogenous antioxidant, is used by GPx to reduce peroxides and peroxyl free radicals. GSSG is reduced back to GSH by GR. The GSSG: GSH ratio is a primary marker for the cellular redox state. An increase in the GSSG: GSH ratio suggests increased oxidative stress. After systemic administration of $30 \mathrm{~nm}$ ceria, the GSSG: GSH ratio was significantly increased in the hippocampus from $1 \mathrm{~h}$ to $30 \mathrm{~d}$, indicating elevated oxidative stress, while a decreased GSSG: GSH ratio was observed at $90 \mathrm{~d}$, implying restoration of cellular redox status. These glutathione-related data are presented and discussed in detail in a separate paper recently submitted (Graham et al., 2013).

3.2.2. Induction of Tier 1 oxidative stress responses 1 and $20 \mathrm{~h}$ after nanoceria infusion: An increase in PC, 3NT and HO-1 levels was inversely related to phase II antioxidant enzyme activities 
Phase II antioxidant enzymes such as GPx, GR, Cat and SOD are markers for the Tier 1 oxidative stress response (per the HOS model). Both levels as well as activities of GPx and Cat were induced 1 and $20 \mathrm{~h}$ after nanoceria exposure (Figures $3 \mathrm{a}$ and b). While GPx and Cat levels were elevated 30 days after nanoceria infusion, their enzyme activities were significantly decreased from 1-30 d (Figures 3a and b). Inhibition in enzyme activity in spite of elevated enzyme levels may imply oxidative modification of enzyme proteins. However, $90 \mathrm{~d}$ after nanoceria dosing the levels and activities of phase-II enzymes had generally returned to control levels, except Cat activity, which was still elevated (Figures 3a and b). The GR level was decreased after $20 \mathrm{~d}$ and increased after $30 \mathrm{~d}$, while GR-activity remained unchanged at all time points except after $30 \mathrm{~d}$ when it was significantly elevated (data not shown). Manganese-SOD levels and activity remained unaffected by the nanoceria (data not shown).

Changes in PC and 3NT levels showed a reverse trend compared to changes in GPx and Cat activities. The decrease in PC and 3NT levels at earlier time points (1 and $20 \mathrm{~h})$ and increase 1, 7 and $30 \mathrm{~d}$ after nanoceria infusion (Figure 4), suggest a failing of the Tier 1 antioxidant defense response at later time points. Along with PC and 3NT levels, the level of oxidative stressinduced HO-1 and Hsp 70 also were increased (Figure 5), although Hsp 70 showed few temporal variations, except a significant decrease at $20 \mathrm{~h}$ and a significant increase at $30 \mathrm{~d}$ (Figure 5).

\subsubsection{Induction of Tier 2 oxidative stress response 1, 7, and $30 \mathrm{~d}$ after nanoceria infusion}

Levels of the inflammatory cytokine and Tier 2 marker (IL-1 $\beta$ ) did not show any change at the earlier time points ( 1 and $20 \mathrm{~h}$ ), but their levels increased 1 and $30 \mathrm{~d}$ after nanoceria dosing (Figure 6). The modulation of IL-1 $\beta$ levels was in agreement with the change in PC, 3NT and 
HO-1 levels, whereas inversely related to GPx and Cat activity. Cytokine TNF- $\alpha$ level decreased at $1 \mathrm{~h}$ but did not increase after any time point, and changes were not significant (Figure 6).

\subsubsection{Induction of Tier 3 oxidative stress response $30 \mathrm{~d}$ after nanoceria treatment}

Levels of the pro-apoptosis and Tier-3 marker, pro-caspase-3, were increased at $30 \mathrm{~d}$ (Figure 7). Elevated levels of the pro-apoptosis marker were temporally concurrent with increased PC, 3NT, HO-1 and IL-1 $\beta$ levels as well as decreased phase-II enzyme activities $30 \mathrm{~d}$ after nanoceria treatment.

\subsubsection{An autophagy marker appears at $7 d, 30 d$ and at $90 d$ [the 90 day result is below control]}

Escalated oxidative stress can activate autophagy responses (Gottlieb et al., 2010, Hariharan et al., 2011, Marambio et al., 2010) to recycle or restore altered macromolecules and organelles. Oxidatively-modified proteins are selectively removed by chaperon-mediated autophagy (Kaushik et al., 2006, Kiffin et al., 2004). Levels of the autophagy marker LC-3AB, were concomitantly induced with induction of the GSSG: GSH ratio, PC, and 3NT levels at 7 and $30 \mathrm{~d}$ along with an increase in Hsp70 levels at 30 d. On the other hand at $90 \mathrm{~d}$, LC-3AB levels went down as the GSSG: GSH ratio returned to normalcy and PC and 3NT levels were suppressed (Figure 8 ). Concurrently increased LC-3AB and Hsp70 could potentially activate a chaperonemediated autophagy process or Tier-4 response, which could lead to clearance of oxidativelymodified proteins, enzymes, and other biomolecules and therefore restoring the cellular redox balance at $90 \mathrm{~d}$. 


\section{Discussion}

Studies on nanoceria have revealed both pro- and anti-oxidant behavior. A review summarizes the evidence available on free radical scavenging ability of nanoceria under pre-induced oxidative stress conditions (Karakoti et al., 2009a). However, $30 \mathrm{~nm}$ ceria was shown to induce ROS in BEAS-2B cells in culture after $24 \mathrm{~h}$ incubation in a dose-dependent manner in the absence of any external ROS source. In the same experiment nanoceria decreased cell viability in a size-independent manner (Park et al., 2008). Our previous studies with $5 \mathrm{~nm}$ nanoceria showed the absence of oxidative stress effects in rat brain 1 and $20 \mathrm{~h}$ post infusion (Hardas et al., 2010) and pro-oxidant effects in rat brain and liver $30 \mathrm{~d}$ after infusion (Hardas et al., 2012, Tseng et al., 2012). Another study with $30 \mathrm{~nm}$ nanoceria reported induction of PC levels in liver and reduction in spleen in a time-dependent manner from 1 to $30 \mathrm{~d}$ (Yokel et al., 2012). In the same study, PC levels were found to be significantly reduced $90 \mathrm{~d}$ after nanoceria in both liver and spleen. The present work is an extension of our previous work with nanoceria. We demonstrated that a single $30 \mathrm{~nm}$ nanoceria infusion, which does not lead to any appreciable nanoceria in brain (Yokel et al., 2012) and in table 1 of this report, induced an oxidative stress response and secondary oxidative stimulus in a time-dependent manner in the hippocampus.

Effects of ceria on oxidative stress parameters are robust. The changes in oxidative stress parameters that we saw are on the order of what we have reported in neurodegenerative disorders like Alzheimer disease (Sultana et al., 2009, Sultana et al., 2006, Butterfield et al., 2013), putting the severity of the biological responses in this study in perspective. A positive control was not included because at the time we initiated this study we could not find a relevant metal-based ENM that had demonstrated effects on rodent brain oxidative stress endpoints that we felt was an 
appropriate positive control. The current work is also the first comprehensive study that validates the HOS model with an in vivo toxicological evaluation of an ENM (Nel et al., 2006). Furthermore, our results revealed that biopersistence of nanoceria in vivo leads to a new tier (Tier 4), an extension of the HOS model, in which oxidative stress markers return to normalcy. Various oxidative stress response pathways can be initiated depending on the severity of incidences such as oxidative insult, free radical generation, or decline in cellular redox state mediated by external or internal stimuli (Chia et al., 2010, Lee et al., 2008, Speciale et al., 2011). In the current study, the systemic, onetime infusion of $30 \mathrm{~nm}$ nanoceria demonstrated aspects of all three tiers of the HOS model in the rat hippocampus. The nanoceria treatment elevated the GSSG: GSH ratio at early time points ( 1 and $20 \mathrm{~h}$ ), which would have induced the Tier 1 defense response. As a result, GPx and Cat levels as well as their activities were increased and PC and 3NT levels were suppressed, which illustrates cytoprotection (Figure 9a and b). However, the Tier 1 defense appears to not hold up against the oxidative stress induced by biopersistent nanoceria, as the GSSG: GSH ratio was increased after $1 \mathrm{~d}$ and remained elevated through the $30^{\text {th }}$ day after nanoceria administration. Inflammatory cytokine IL-1 $\beta$ levels were also induced 1 and $30 \mathrm{~d}$ after nanoceria infusion. Thus with activation of inflammatory cytokines, a.k.a the Tier 2 response after $1 \mathrm{~d}, \mathrm{PC}$ and 3NT levels were also increased (Figure 9a and b). The oxidative stress inducible heat shock family proteins (HSP) HO-1 and Hsp70 levels were concomitantly induced with PC and 3NT levels 1, 7 and $30 \mathrm{~d}$ after ceria infusion. Usually, such stress-induced molecules or proteins not only exhibit cytoprotection against immediate threat but also reinforce the cellular defense against possible future menaces (Morse et al., 2005). HO-1 also is a phase-II antioxidant enzyme, and nitrosative stress has been associated with its induction (Calabrese et al., 2002, Ghosh et al., 2011, Mancuso et al., 2009, Poon et al., 2004). In the case of HO-1, while 
it removes toxic heme, it also produces biliverdin, a precursor for the antioxidant bilirubin (Barone et al., 2009, Mancuso et al., 2012). HO-1 has been shown to be neuroprotective against UV-light, lipopolysaccharide, heme, and various oxidative stress stimuli, especially against nitrosative stress (Calabrese et al., 2007, Calabrese et al., 2002, Calabrese et al., 2004, Ghosh et al., 2011, Mancuso et al., 1999, Poon et al., 2004). Hsp70 acts as a chaperone for other proteins by assisting protein folding and protein transport across membranes within the cell (Brown, 2007, Poon et al., 2004, Yenari et al., 1999). Additionally Hsp70 helps to prevent protein aggregation induced by oxidative modification as well as aid transport for the clearance mechanism of unfolded, aggregated proteins (Mayer et al., 2005, Young et al., 2003, Hartl et al., 2002, Calabrese et al., 2004, Calabrese et al., 2007). However, in spite of induction of cytoprotective HSP levels, downstream consequences of initiation of Tier 2-pro-inflammatory cytokine responses and elevated GSSG:GSH ratio lead to activation of the pro-apoptotic signaling cascade (Shakibaei et al., 2007, Nesic et al., 2004), a.k.a the Tier 3 response observed after $30 \mathrm{~d}$. The pro-caspase-3 levels were induced, concurrent with elevated PC, 3NT and IL-1 $\beta$ levels (Figure 9a and b). Pro-caspase-3 protein is the precursor for caspase-3, and its levels were measured to estimate the possibility of activation of caspase-3, the final executioner of cellular apoptosis.

Simply extending the trajectory of the Tier 1 to Tier 3 of the HOS model, we were expecting to find profound deleterious effects on cellular redox status after $90 \mathrm{~d}$. But quite to the contrary, we believe for the first time we have demonstrated that the GSSG: GSH ratio was restored back to control levels as phase-II antioxidant levels and activities (except Cat activity was increased), PC, 3NT, HSP levels were returned to normalcy after $90 \mathrm{~d}$ as shown in Figure 9a and b. In brief, after $90 \mathrm{~d}$, there was no sign of oxidative stress in the hippocampus, let alone damage 
caused by oxidative stress. As elevated oxidative stress can negatively affect cellular assembly leading to misfolded or damaged proteins and organelles and protein aggregation, the efficient removal of such damaged cellular material from the cytoplasm is essential for cell survival and adaptation. Cells can avoid accumulation of potentially toxic misfolded protein aggregates by accessing an array of mechanisms; one such mechanism is the lysosomal-degradation autophagy process (Ryhänen et al., 2009). The autophagy marker LC-3AB showed a increasing trend from 7 to $30 \mathrm{~d}$, coinciding with the markers of escalating oxidative stress (Figure 9a). Among the three types of autophagy mechanisms, chaperone-mediated autophagy was shown to selectively clear out oxidatively-modified proteins from the cytoplasm during aging and age-related disorders in mammalian cells (Kaushik et al., 2006, Kiffin et al., 2004, Ryhänen et al., 2009). Hsp70 assists in chaperone-mediated autophagy (Dice, 2007, Ryhänen et al., 2009, Witt, 2010). Consistent with the findings of LC-3AB, Hsp70 also showed an increasing trend with accelerating oxidative stress from 1 to $30 \mathrm{~d}$ (Figure 9a and b). Hsp70 is known to protect cells from endoplasmic reticulum-stress induced apoptosis (Gupta et al., 2010). Hsp70 and autophagy can play a significant role against the progression of neurodegenerative diseases (Wilhelmus et al., 2007, Witt, 2010) in which Hsp70 modulates protein aggregation as well as removes hazardous protein aggregates (Poon et al., 2004). Thus, restoration of the redox balance observed after $90 \mathrm{~d}$ following ceria administration might have been the downstream consequence of activation of the autophagy process (7 d) and/or induction of Hsp70 (30 d), which might have cleared damaged macromolecules and organelles, and aided in cell adaptation. In the field of biology and medicine, cellular cleansing is known as hormesis, defined as “....an adaptive response of cells and organisms to a moderate (usually intermittent) stress" (Mattson, 2008). Autophagy may increase organismal fitness by obstructing cell death and increasing hormesis (Rubinsztein et al., 
2011), whereas induction of HSPs can be an effector to promote hormesis-mediated therapy in neurodegenerative conditions (Calabrese et al., 2010a, Calabrese et al., 2010b). Although the preponderance of evidence of this study supports the notion that the recovery to the normal state occurs after a lengthy period, that we term Tier 4 , recovery is potentially possible at every tier (Halliwell et al., 2007). Therefore, based on our current findings, we propose that the restoration of the normal redox status of the hippocampus $90 \mathrm{~d}$ after nanoceria infusion is an extension to the original hierarchical oxidative stress model, as a Tier 4 response (Figure 9b).

The findings presented in this report, although unexpected, are consistent with the fate of nanoceria in the mammal. The percentage of nanoceria absorbed from the lungs and gastrointestinal tract is very low (Geraets et al., 2012, He et al., 2010, Hirst et al., 2013, Park et al., 2009), requiring systemic or local administration to achieve appreciable concentrations in organs. Nanoceria is rapidly cleared from blood into mononuclear phagocyte organs, as are most nanoparticles that are not surface-coated to target specific sites (Glazer et al., 2011, Pouliquen et al., 1991, Riviere, 2009, Yokel et al., 2012). There is very little elimination of nanoceria from the mammal (Pairon et al., 1995, Yokel et al., 2012). Although quite insoluble (He et al., 2010), we have seen some dissolution of nanoceria in the liver 90 days after its intravenous administration, that presumably released cerium ion, some of which appears to have resulted in formation of ultra-small nanoceria particles in the liver that inherently have, due to their small size, a greater percentage of Ce III on their surface, the valence state that enables the antioxidant effects of nanoceria (Graham et al., 2013). This biotransformation is presumably related to the temporal change in the oxidative stress markers in the brain. Nanoceria is being investigated by many as a potential antioxidant, anti-inflammatory therapeutic (Das et al, 20131 Wason and Zhao, 2013). As this current study shows, nanoceria's effects on oxidant stress endpoints change over time. It 
is essential to understand the pro- and/or anti-oxidant effects of nanoceria during its very

prolonged residence in mammals, including humans, to know if nanoceria produces beneficial or detrimental effects, particularly if it is used as a therapeutic to reduce detrimental effects of inflammatory diseases. Further work assessing the long-term effects of nanoceria in models of short- and long-duration inflammatory disease is necessary.

\section{Conclusion}

Although it is true that many times toxicity can be followed by recovery, however depending on the severity of the insult, recovery processes may or may not take place. Furthermore, there is no literature evidence on recovery response after in vivo NP particle toxicity, and this is certainly the first in vivo study that reports the time dependent ENM toxicity followed by recovery. The significance of the current study is twofold: a) this is the first demonstration of the hierarchical oxidative stress model in brain or in vivo, and b) this study enabled us to expand the three-tiered HOS model to Tier 4. However, there is a need to follow and test the extended hierarchical oxidative stress model with various types and sizes of ENMs vs. time after exposure, to get a better understanding of oxidative stress effects induced by ENMs. The findings of this study reassert the importance of oxidative stress effects of bio persistent ceria ENM and its implications to its proposed medical or pharmaceutical applications. We believe that the current study will serve as a basis for beginning this large task.

\section{Conflict of interest}

None of the authors have any conflicts of interest.

\section{Acknowledgements}


This work was supported by United States Environmental Protection Agency Science to Achieve Results [grant number RD-833772]. Although the research described in this article has been funded wholly or in part by the United States Environmental Protection Agency through STAR Grant RD-833772, it has not been subjected to the Agency's required peer and policy review and therefore does not necessarily reflect the views of the Agency and no official endorsement should be inferred. 


\section{References}

Auffan, M., Rose, J., Orsiere, T., De Meo, M., Thill, A., Zeyons, O., Proux, O., Masion, A., Chaurand, P., Spalla, O., Botta, A., Wiesner, M. R. \& Bottero, J.-Y. 2009. $\mathrm{CeO}_{2}$ nanoparticles induce DNA damage towards human dermal fibroblasts in vitro. Nanotoxicology 3: 161-171.

Babu, S., Cho, J.-H., Dowding, J. M., Heckert, E., Komanski, C., Das, S., Colon, J., Baker, C. H., Bass, M., Self, W. T. \& Seal, S. 2010. Multicolored redox active upconverter cerium oxide nanoparticle for bio-imaging and therapeutics. Chem Commun 46: 6915-6917.

Barone, E., Trombino, S., Cassano, R., Sqambato, A., De Paola, B., Di Stasio, E., Picci, N., Preziosi, P. \& Mancuso, C. 2009. Characterization of the S-Denitrosylating Activity of Bilirubin. J Cell Mol Med $8 B$.

Beal, M. F. 2002. Oxidatively modified proteins in aging and disease. Free Radical Bio Med 32: 797-803.

Brown, I. R. 2007. Heat shock proteins and protection of the nervous system. Ann NY Acad Sci 1113: 147-158.

Brunner, T. J., Wick, P., Manser, P., Spohn, P., Grass, R. N., Limbach, L. K., Bruinink, A. \& Stark, W. J. 2006. In vitro cytotoxicity of oxide nanoparticles: comparison to asbestos, silica, and the effect of particle solubility. Environ Sci \& Tech 40: 4374-4381.

Butterfield, D. A., Swomley, A. M. \& Sultana, R. 2013. Amyloid $\beta$-peptide (1-42)-induced oxidative stress in Alzheimer Disease: Importance in disease pathogenesis and progression. Antioxid Redox Sign 19: 823-835.

Buzea, C., Pacheco, I. \& Robbie, K. 2007. Nanomaterials and Nanoparticles: Sources and Toxicity. Biointerphases 2: MR17-MR71.

Cai, X., Sezate, S. A., Seal, S. \& McGinnis, J. F. 2012. Sustained protection against photoreceptor degeneration in tubby mice by intravitreal injection of nanoceria. Biomaterials 33: 8771-81.

Calabrese, V., Cornelius, C., Dinkova-Kostova, A. T., Calabrese, E. J. \& Mattson, M. P. 2010a. Cellular stress responses, the hormesis paradigm, and vitagenes: Novel targets for therapeutic intervention in neurodegenerative disorders. Antioxid Redox Sign 13: 1763-811.

Calabrese, V., Cornelius, C., Trovato, A., Cavallaro, M., Mancuso, C., Di Rienzo, L., Condorelli, D., De Lorenzo, A. \& Calabrese, E. J. 2010b. The hormetic role of dietary antioxidants in free radicalrelated diseases. Curr Pharm Des 16: 877-883.

Calabrese, V., Guagliano, E., Sapienza, M., Panebianco, M., Calafato, S., Puleo, E., Pennisi, G., Mancuso, C., Allan Butterfield, D. \& Stella, A. 2007. Redox regulation of cellular stress response in aging and neurodegenerative disorders: Role of vitagenes. Neurochem Res 32: 757-773.

Calabrese, V., Scapagnini, G., Ravagna, A., Fariello, R. G., Giuffrida Stella, A. M. \& Abraham, N. G. 2002. Regional distribution of heme oxygenase, HSP70, and glutathione in brain: Relevance for endogenous oxidant/ antioxidant balance and stress tolerance. J Neurosci Res 68: 65-75.

Calabrese, V., Stella, A. M. G., Butterfield, D. A. \& Scapagnini, G. 2004. Redox regulation in neurodegeneration and longevity: Role of the heme oxygenase and HSP70 systems in brain stress tolerance. Antioxid Redox Sign 6: 895-913.

Cassee, F. R., van Balen, E. C., Singh, C., Green, D., Muijser, H., Weinstein, J. \& Dreher, K. 2011. Exposure, health and ecological effects review of engineered nanoscale cerium and cerium oxide associated with its use as a fuel additive. Crit Rev Toxicol 41: 213-229.

Celardo, I., De Nicola, M., Mandoli, C., Pedersen, J. Z., Traversa, E. \& Ghibelli, L. 2011a. Ce ${ }^{3+}$ Ions determine redox-dependent anti-apoptotic effect of cerium oxide nanoparticles. ACS Nano 5: 4537-4549.

Celardo, I., Pedersen, J. Z., Traversa, E. \& Ghibelli, L. 2011b. Pharmacological potential of cerium oxide nanoparticles. Nanoscale 3: 1411-1420. 
Chaudhury, K., Babu, K. N., Singh, A. K., Das, S., Kumar, A. \& Seal, S. 2013. Mitigation of endometriosis using regenerative cerium oxide nanoparticles. Nanomed 9: 439-48.

Chen, J., Patil, S., Seal, S. \& McGinnis, J. F. 2006. Rare earth nanoparticles prevent retinal degeneration induced by intracellular peroxides. Nat Nanotechnol 1: 142-150.

Chen, S., Hou, Y., Cheng, G., Zhang, C., Wang, S. \& Zhang, J. 2013. Cerium oxide nanoparticles protect endothelial cells from apoptosis induced by oxidative stress. Biol Trace Elem Res 6: 6.

Chia, A. J. L., Goldring, C. E., Kitteringham, N. R., Wong, S. Q., Morgan, P. \& Park, B. K. 2010. Differential effect of covalent protein modification and glutathione depletion on the transcriptional response of Nrf2 and NF-KB. Biochem Pharmacol 80: 410-421.

Cho, W.-S., Duffin, R., Poland, C. A., Howie, S. E. M., MacNee, W., Bradley, M., Megson, I. L. \& Donaldson, K. 2010. Metal oxide nanoparticles induce unique inflammatory footprints in the lung: important implications for nanoparticle testing. Environ Health Persp 118: 1699-1706.

Ciofani, G., Genchi, G. G., Liakos, I., Cappello, V., Gemmi, M., Athanassiou, A., Mazzolai, B. \& Mattoli, V. 2013. Effects of cerium oxide nanoparticles on PC12 neuronal-like cells: Proliferation, differentiation, and dopamine Secretion. Pharm Res 10: 10.

Colon, J., Hsieh, N., Ferguson, A., Kupelian, P., Seal, S., Jenkins, D. W. \& Baker, C. H. 2010. Cerium oxide nanoparticles protect gastrointestinal epithelium from radiation-induced damage by reduction of reactive oxygen species and upregulation of superoxide dismutase 2. Nanomed-Nanotechnol. 6: 698-705.

D'Angelo, B., Santucci, S., Benedetti, E., Di Loreto, S., Phani, R. A., Falone, S., Amicarelli, F., Ceru, M. P. \& Cimini, A. 2009. Cerium oxide nanoparticles trigger neuronal survival in a human Alzheimer disease model by modulating BDNF pathway. Curr Nanosci 5: 167-176.

Dalle-Donne, I., Rossi, R., Giustarini, D., Milzani, A. \& Colombo, R. 2003. Protein carbonyl groups as biomarkers of oxidative stress. Clin Chim Acta 329: 23-38.

Dan, M., Wu, P., Grulke, E. A., Graham, U. M., Unrine, J. M. \& Yokel, R. A. 2012. Ceria engineered nanomaterial distribution in and clearance from blood: Size matters. Nanomed 7: 95-110.

Das, M., Patil, S., Bhargava, N., Kang, J. F., Riedel, L. M., Seal, S. \& Hickman, J. J. 2007. Auto-catalytic ceria nanoparticles offer neuroprotection to adult rat spinal cord neurons. Biomaterials 28: 19181925.

Das, S., Singh, S., Dowding, J. M., Oommenc, S., Kumar, A., Sayle, T. X. T., Saraf, S., Patra, C. R., Vlahakis, N. E., Sayle, D. C., Self, W. T. \& Seal, S. 2012. The induction of angiogenesis by cerium oxide nanoparticles through the modulation of oxygen in intracellular environments. Biomaterials 33 : 7746-7755.

Das, S., Dowding, J.M., Klump, K.E., McGinni,s J.F., Self, W., Seal, S. 2013. Cerium oxide nanoparticles: applications and prospects in nanomedicine. Nanomedicine (London, U. K.) 8: 1483-1508.

Dice, J. F. 2007. Chaperone-mediated autophagy. Autophagy 3: 295-9.

Estevez, A. Y., Pritchard, S., Harper, K., Aston, J. W., Lynch, A., Lucky, J. J., Ludington, J. S., Chatani, P., Mosenthal, W. P., Leiter, J. C., Andreescu, S. \& Erlichman, J. S. 2011. Neuroprotective mechanisms of cerium oxide nanoparticles in a mouse hippocampal brain slice model of ischemia. Free Radical Bio Med 51: 1155-1163.

Feng, X., Sayle, D. C., Wang, Z. L., Paras, M. S., Santora, B., Sutorik, A. C., Sayle, T. X. T., Yang, Y., Ding, Y., Wang, X. \& Her, Y.-S. 2006. Converting ceria polyhedral nanoparticles into single-crystal nanospheres. Science 312: 1504-1508.

Geraets, L., Oomen, A. G., Schroeter, J. D., Coleman, V. A. \& Cassee, F. R. 2012. Tissue distribution of inhaled micro- and nano-sized cerium oxide particles in rats: Results from a 28-day exposure study. Toxicol Sci 127: 463-473.

Ghosh, N., Ghosh, R. \& Mandal, S. C. 2011. Antioxidant protection: A promising therapeutic intervention in neurodegenerative disease. Free Radical Res 45: 888-905. 
Glazer, E. S., Zhu, C., Hamir, A. N., Borne, A., Thompson, C. S. \& Curley, S. A. 2011. Biodistribution and acute toxicity of naked gold nanoparticles in a rabbit hepatic tumor model. Nanotoxicology 5: 459-468.

Gottlieb, R. A. \& Carreira, R. S. 2010. Autophagy in health and disease. 5. Mitophagy as a way of life. Am J Physiol Cell Physiol 299: C203-C210.

Graham, U. M., Tseng, M., Jasinski, J., Hardas, S. S., Yokel, R. A., Unrine, J., Sultana, R., Davis, B., Grulke, E. \& Butterfield, D. A. 2013. In vivo bioprocessing of nanoceria is associated with decreased oxidative stress: Relevance to proposed nanoceria use and potential toxicity; submitted for publication

Gupta, S., Deepti, A., Deegan, S., Lisbona, F., Hetz, C. \& Samali, A. 2010. HSP72 protects cells from ER stress-induced apoptosis via enhancement of IRE1 $\alpha$-XBP1 signaling through a physical interaction. PLoS Biol 8.

Halliwell, B. \& Gutteridge, J. M. C. 2007. Free Radicals in Biology and Medicine. Clarendon Press Oxford.

Hardas, S. S., Butterfield, D. A., Sultana, R., Tseng, M. T., Dan, M., Florence, R. L., Unrine, J. M., Graham, U. M., Wu, P., Grulke, E. A. \& Yokel, R. A. 2010. Brain distribution and toxicological evaluation of a systemically delivered engineered nanoscale ceria. Toxicol Sci 116: 562-576.

Hardas, S. S., Sultana, R., Warrier, G., Dan, M., Florence, R. L., Wu, P., Grulke, E. A., Tseng, M. T., Unrine, J. M., Graham, U. M., Yokel, R. A. \& Butterfield, D. A. 2012. Rat brain pro-oxidant effects of peripherally administered $5 \mathrm{~nm}$ ceria 30 days after exposure. NeuroToxicology 33: 1147-1155.

Hariharan, N., Zhai, P. \& Sadoshima, J. 2011. Oxidative stress stimulates autophagic flux during ischemia or reperfusion. Antioxid Redox Sign 14: 2179-2190.

Hartl, F. U. \& Hayer-Hartl, M. 2002. Molecular chaperones in the cytosol: from nascent chain to folded protein. Science 295: 1852-1858.

He, X., Zhang, H., Ma, Y., Bai, W., Zhang, Z., Lu, K., Ding, Y., Zhao, Y. \& Chai, Z. 2010. Lung deposition and extrapulmonary translocation of nano-ceria after intratracheal instillation Nanotechnology 21: 285103-285111.

Heckert, E. G., Karakoti, A. S., Seal, S. \& Self, W. T. 2008. The role of cerium redox state in the SOD mimetic activity of nanoceria. Biomaterials 29: 2705-2709.

Hirst, S. M., Karakoti, A., Singh, S., Self, W., Tyler, R., Seal, S. \& Reilly, C. M. 2013. Bio-distribution and in vivo antioxidant effects of cerium oxide nanoparticles in mice. Environ Toxicol 28: 1-12.

Hirst, S. M., Karakoti, A. S., Tyler, R. D., Sriranganathan, N., Seal, S. \& Reilly, C. M. 2009. Antiinflammatory properties of cerium oxide nanoparticles. Small 5: 2848-2856.

Hissin, P. J. \& Hilf, R. 1976. A fluorometric method for determination of oxidized and reduced glutathione in tissues. Analytical Biochemistry 74: 214-226.

http://www.toxicology.org/ai/air/air6.asp.

Ishigure, N. 1999. Calculation of retention and excretion of some selected radionuclides after acute intake by inhalation according to new ICRP dose estimation models J Nucl Sci Technol 36830 838.

Karakoti, A., Singh, S., Dowding, J. M., Seal, S. \& Self, W. T. 2009a. Redox-active radical scavenging nanomaterials. Chem Soc Rev 39: 4422-4432.

Karakoti, A. S., Singh, S., Kumar, A., Malinska, M., Kuchibhatla, S. V. N. T., Wozniak, K., Self, W. T. \& Seal, S. 2009b. PEGylated Nanoceria as radical scavenger with tunable redox chemistry. J Am Chem Soc 131: 14144-14145.

Karakoti, A. S., Tsigkou, O., Yue, S., Lee, P. D., Stevens, M. M., Jones, J. R. \& Seal, S. 2010. Rare earth oxides as nanoadditives in 3-D nanocomposite scaffolds for bone regeneration. Journal of Materials Chemistry 20: 8912-8919.

Kaushik, S. \& Cuervo, A. M. 2006. Autophagy as a cell-repair mechanism: Activation of chaperonemediated autophagy during oxidative stress. Mol Aspects Med 27: 444-454. 
Kiffin, R., Christian, C., Knecht, E. \& Cuervo, A. M. 2004. Activation of chaperone-mediated autophagy during oxidative stress. Mol Biol Cell 15: 4829-4840.

Korsvik, C., Patil, S., Seal, S. \& Self, W. T. 2007. Superoxide dismutase mimetic properties exhibited by vacancy engineered ceria nanoparticles. Chem Commun: 1056-1058.

Lee, H.-R., Cho, J.-M., Shin, D.-h., Yong, C., Choi, H.-G., Wakabayashi, N. \& Kwak, M.-K. 2008. Adaptive response to GSH depletion and resistance to L-buthionine-(S,R)-sulfoximine: involvement of Nrf2 activation. Mol Cell Biochem 318: 23-31.

Li, N., Alam, J., Venkatesan, M. I., Eiguren-Fernandez, A., Schmitz, D., Di Stefano, E., Slaughter, N., Killeen, E., Wang, X., Huang, A., Wang, M., Miguel, A. H., Cho, A., Sioutas, C. \& Nel, A. E. 2004. Nrf2 is a key transcription factor that regulates antioxidant defense in macrophages and epithelial cells: Protecting against the proinflammatory and oxidizing effects of diesel exhaust chemicals. J Immunol 173: 3467-3481.

Lin, W., Huang, Y.-w., Zhou, X.-D. \& Ma, Y. 2006. Toxicity of cerium oxide nanoparticles in human lung cancer cells. Int J Toxicol 25: 451-457.

Lustgarten, C. S., Cuddihy, R. G., Boecker, B. B. \& Huber, N. 1974. Biliary excretion of cerium-144 following inhalation of cerium-144 citrate by rats. Annual Report of the Inhalation Toxicology Research Institute Lovelace Biomedical and Environmental Research Institute.

Ma, J. Y., Zhao, H., Mercer, R. R., Barger, M., Rao, M., Meighan, T., Schwegler-Berry, D., Castranova, V. \& $\mathrm{Ma}$, J. K. 2011. Cerium oxide nanoparticle-induced pulmonary inflammation and alveolar macrophage functional change in rats. Nanotoxicology 5: 312-25.

Mancuso, C. \& Barone, E. 2009. The heme oxygenase/ biliverdin reductase pathway in drug research and developement. Curr Drug Metabol 10: 579-594.

Mancuso, C., Barone, E., Guido, P., Miceli, F., Di Domenico, F., Perluigi, M., Santangelo, R. \& Paolo, P. 2012. Inhibition of lipid peroxidation and protein oxidation by endogeneous and exogeneous antioxidants in rat brain microsomes in vitro. Neurosci Lett 518: 101-105.

Mancuso, C., Ragazzoni, E., Tringali, G., Liberale, I., Preziosi, P., Grossman, A. \& Navarra, P. 1999. Inhibition of heme oxygenase in the central nervous system potentiates endotoxin-induced vasopressin release in the rat. J Neuroimmunol 99: 189-194.

Marambio, P., Toro, B., Sanhueza, C., Troncoso, R. T., Parra, V., Verdejo, H., García, L., Quiroga, C., Munafo, D., Díaz-Elizondo, J., Bravo, R., González, M.-J., Diaz-Araya, G., Pedrozo, Z., Chiong, M., Isabel Colombo, M. \& Lavandero, S. 2010. Glucose deprivation causes oxidative stress and stimulates aggresome formation and autophagy in cultured cardiac myocytes. Biochim Biophys Acta 18: 509-518.

Mattson, M. P. 2008. Hormesis defined. Ageing Res Rev 7: 1-7.

Mayer, M. \& Bukau, B. 2005. Hsp70 chaperones: Cellular functions and molecular mechanism. Cellular and Molecular Life Sciences 62: 670-684.

Molin, S., Gazda, M., Jasinski, P. \& Nowakowski, A. 2008. Electrical properties of porous nanocrystalline undoped ceria oxygen sensor. Elektronika 49: 253-254.

Morse, D. \& Choi, A. M. K. 2005. Heme oxygenase-1: From bench to bedside. Am J Resp Crit Care 172: 660-670.

Nel, A., Xia, T., Madler, L. \& Li, N. 2006. Toxic potential of materials at the nanolevel. Science 311: 622627.

Nesic, O., Xu, G.-Y., McAdoo, D., Westlund High, K., Hulsebosch, C. \& Perez-Polo, R. 2004. IL-1Beta receptor antagonist prevents apoptosis and caspase-3 activation after spinal cord injury. J Neurotrauma 18: 947-956.

NIEHS 2006. Chemical information profile for ceric oxide [CAS No. 1306-38-3] Supporting nomination for toxicological evaluation by the national toxicology program. Integrated Laboratory Systems. In: National Toxicological Program, NIEHS, Research Triangle Park, NC, USA; p 21. . 
Niu, J., Azfer, A., Rogers, L. M., Wang, X. \& Kolattukudy, P. E. 2007. Cardioprotective effects of cerium oxide nanoparticles in a transgenic murine model of cardiomyopathy. Cardiovasc Res 73: 549559.

Niu, J., Wang, K. \& Kolattukudy, P. E. 2011. Cerium oxide nanoparticles inhibits oxidative stress and nuclear factor-KB activation in H9c2 cardiomyocytes exposed to cigarette smoke extract. J Pharm Exp Ther 338: 53-61.

OECD. Organisation for Economic Co-operation and Development. List of manufactured nanomaterials and list of endpoints for phase one of the OECD testing programme. In series on the safety of manufactured nanomaterials environment directorate. Joint meeting of the chemicals committee and the working party on chemicals, pesticides and biotechnology., 2008.

OECD. Organisation for Economic Co-operation and Development. Current developements/ activities on the safety of manufactured nanomaterials. . OECD Environment, health and safety publications series on the safety of manufactured nanomaterials., 2010. Available at: http://search.oecd.org/officialdocuments/displaydocumentpdf/?doclanguage=en\&cote=ENV/J $\mathrm{M} / \mathrm{MONO}(2010) 4$.

Pairon, J. C., Roos, F., Sebastien, P., Chamak, B., Abd-Alsamad, I., Bernaudin, J. F., Bignon, J. \& Brochard, P. 1995. Biopersistence of cerium in the human respiratory tract and ultrastructural findings. Am J Ind Med 27: 349-358.

Park, B., Martin, P., Harris, C., Guest, R., Whittingham, A., Jenkinson, P. \& Handley, J. 2007. Initial in vitro screening approach to investigate the potential health and environmental hazards of Envirox $^{\mathrm{TM}}$ - A nanoparticulate cerium oxide diesel fuel additive. Part Fibre Toxicol 4.

Park, E. J., Choi, J., Park, Y. K. \& Park, K. 2008. Oxidative stress induced by cerium oxide nanoparticles in cultured BEAS-2B cells. Toxicology 245: 90-100.

Park, E. J., Park, Y. K. \& Park, K. 2009. Acute toxicity and tissue distribution of cerium oxide nanoparticles by a single oral administration in rats. Toxicol Res 25: 79-84.

Pirmohamed, T., Dowding, J. M., Singh, S., Wasserman, B., Heckert, E., Karakoti, A. S., King, J. E. S., Seal, S. \& Self, W. T. 2010. Nanoceria exhibit redox state-dependent catalase mimetic activity. Chem Commun 46: 2736-2738.

Poon, H. F., Calabrese, V., Scapagnini, G. \& Butterfield, D. A. 2004. Free radicals: Key to brain aging and heme oxygenase as a cellular response to oxidative stress. J Gerontol A Biol Sci Med Sci 59: 478493.

Pouliquen, D., Le, J. J. J., Perdrisot, R., Ermias, A. \& Jallet, P. 1991. Iron oxide nanoparticles for use as an MRI contrast agent: pharmacokinetics and metabolism. Magn Reson Imaging 9: 275-283.

Riviere, J. E. 2009. Pharmacokinetics of nanomaterials: An overview of carbon nanotubes, fullerenes and quantum dots. Wiley Interdiscip Rev Nanomed Nanobiotechnol 1: 26-34.

Rodea-Palomares, I., Boltes, K., Fernandez-Pinas, F., Leganes, F., Garcia-Calvo, E., Santiago, J. \& Rosal, R. 2011. Physicochemical characterization and ecotoxicological assessment of $\mathrm{CeO}_{2}$ nanoparticles using two aquatic microorganisms. Toxicol Sci 119: 135-145.

Roh, J. Y., Park, Y. K., Park, K. \& Choi, J. 2010. Ecotoxicological investigation of $\mathrm{CeO}_{2}$ and $\mathrm{TiO}_{2}$ nanoparticles on the soil nematode Caenorhabditis elegans using gene expression, growth, fertility, and survival as endpoints. . Environ Toxicol Pharm 29: 167-172.

Rubinsztein, David C., Mariño, G. \& Kroemer, G. 2011. Autophagy and Aging. Cell 146: 682-695.

Ryhänen, T., Hyttinen, J. M. T., Kopitz, J., Rilla, K., Kuusisto, E., Mannermaa, E., Viiri, J., Holmberg, C. I., Immonen, I., Meri, S., Parkkinen, J., Eskelinen, E.-L., Uusitalo, H., Salminen, A. \& Kaarniranta, K. 2009. Crosstalk between Hsp70 molecular chaperone, lysosomes and proteasomes in autophagy-mediated proteolysis in human retinal pigment epithelial cells. J Cell Mol Med 13: 3616-3631. 
Sahu, T., Singh Bisht, S., Ranjan Das, K. \& Kerkar, S. 2013. Nanoceria: Synthesis and biomedical applications. Curr NanoSci 9: 588-593.

Shakibaei, M., John, T., Seifarth, C. \& Mobasheri, A. L. I. 2007. Resveratrol inhibits IL-1 $\beta$-induced stimulation of caspase-3 and cleavage of PARP in human articular chondrocytes in vitro. Ann NY Acad Sci 1095: 554-563.

Speciale, A., Anwar, S., Ricciardi, E., Chirafisi, J., Saija, A. \& Cimino, F. 2011. Cellular adaptive response to glutathione depletion modulates endothelial dysfunction triggered by TNF- $\alpha$. Toxicol Lett 207: 291-297.

Srinivas, A., Rao, P. J., Selvam, G., Murthy, P. B. \& Reddy, P. N. 2011. Acute inhalation toxicity of cerium oxide nanoparticles in rats. Toxicol Lett 205: 105-115.

Steiner, S., Mueller, L., Popovicheva, O. B., Raemy, D. O., Czerwinski, J., Comte, P., Mayer, A., Gehr, P., Rothen-Rutishauser, B. \& Clift, M. J. 2012. Cerium dioxide nanoparticles can interfere with the associated cellular mechanistic response to diesel exhaust exposure. Toxicol Lett 214: 218-25.

Sultana, R. \& Butterfield, D. A. 2009. Proteomics identification of carbonylated and HNE-bound brain proteins in Alzheimer's disease. Methods Mol Bio 566: 123-135.

Sultana, R., Perluigi, M. \& Butterfield, D. A. 2006. Protein oxidation and lipid proxidation in brain of subjects with Alzheimer's disease: Insights into mechanisms of neurodegeneration from redox proteomics. Antioxid Redox Sign 8: 2021-2037.

Sultana, R., Piroddi, M., Galli, F. \& Butterfield, D. 2008. Protein levels and activity of some antioxidant enzymes in hippocampus of subjects with amnestic mild cognitive impairment. Neurochem Res 33: 2540-2546.

Thill, A., Zeyons, O., Spalla, O., Chauvat, F., Rose, J., Auffan, M. \& Flank, A. M. 2006. Cytotoxicity of $\mathrm{CeO}_{2}$ nanoparticles for Escherichia coli physico-chemical insight of the cytotoxicity mechanism. Environ Sci Technol 40: 6151-6156.

Tseng, M. T., Lu, X., Duan, X., Hardas, S. S., Sultana, R., Wu, P., Unrine, J. M., Graham, U., Butterfield, D. A., Grulke, E. A. \& Yokel, R. A. 2012. Alteration of hepatic structure and oxidative stress induced by intravenous nanoceria. Toxicol Appl Pharmacol 260: 173-182.

Van Hoecke, K., Quik, J. T. K., Mankiewicz-Boczek, J., De Schamphelaere, K. A. C., Elsaesser, A., Van der Meeren, P., Barnes, C., McKerr, G., Vyvyan, H. C. \& Van DeMeent, D. 2009. Fate and effects of $\mathrm{CeO}_{2}$ nanoparticles in aquatic ecotoxicity tests Environ Sci Technol 43: 4537-4546.

Wason, M.S., Zhao, J. 2013. Cerium oxide nanoparticles: potential applications for cancer and other diseases. Am. J. Transl. Res. 5: 126-131.

Wilhelmus, M. M., Waal, R. W. \& Verbeek, M. 2007. Heat shock proteins and amateur chaperones in amyloid-beta accumulation and clearance in Alzheimer's disease. Mol Neurobiol 35: 203-216.

Witt, S. N. 2010. Hsp70 molecular chaperones and Parkinson's disease. Biopolymers 93: 218-228.

Wong, L. L., Hirst, S. M., Pye, Q. N., Reilly, C. M., Seal, S. \& McGinnis, J. F. 2013. Catalytic nanoceria are preferentially retained in the rat retina and are not cytotoxic after intravitreal injection. PLoS ONE 8: 11.

Xia, T., Kovochich, M., Liong, M., Mädler, L., Gilbert, B., Shi, H., Yeh, J. I., Zink, J. I. \& Nel, A. E. 2008. Comparison of the mechanism of toxicity of zinc oxide and cerium oxide nanoparticles based on dissolution and oxidative stress properties. ACS Nano 2: 2121-2134.

Xia, T., Li, N. \& Nel, A. E. 2009. Potential health impact of nanoparticles. Ann Rev Publ Health 30: 137150.

Xiao, G. G., Wang, M., Li, N., Loo, J. A. \& Nel, A. E. 2003. Use of proteomics to demonstrate a hierarchical oxidative stress response to diesel exhaust particle chemicals in a macrophage cell line. J Bio Chem 278: 50781-50790.

Yenari, M. A., Giffard, R. G., Sapolsky, R. M. \& Steinberg, G. K. 1999. The neuroprotective potential of heat shock protein 70 (HSP70). Mol Med Today 5: 525-531. 
Yokel, R. A., Au, T. C., MacPhail, R., Hardas, S. S., Butterfield, D. A., Sultana, R., Tseng, M. T., Dan, M., Florence, R. L., Unrine, J. M., Graham, U. M., Wu, P. \& Grulke, E. A. 2012. Distribution, elimination and biopersistence to 90 days of a systemically-introduced $30 \mathrm{~nm}$ ceria engineered nanomaterial in rats. Toxicol Sci 127: 256-268.

Yokel, R. A., Florence, R. L., Unrine, J. M., Tseng, M. T., Graham, U. M., Wu, P., Grulke, E. A., Sultana, R., Hardas, S. S. \& Butterfield, D. A. 2009. Biodistribution and oxidative stress effects of a systemically-introduced commercial ceria engineered nanomaterial. Nanotoxicology 3: 234-248.

Yokel, R. A. \& MacPhail, R. C. 2011. Engineered nanomaterials: Exposures, hazards, and risk prevention. J Occup Med Toxicol 6.

Yokel, R. A., Tseng, M. T., Dan, M., Unrine, J. M., Graham, U. M., Wu, P. \& Grulke, E. A. 2013. Biodistribution and biopersistence of ceria engineered nanomaterials: Size dependence. Nanomed-Nanotechnol. 9: 398-407.

Young, J. C., Barral, J. M. \& Ulrich Hartl, F. 2003. More than folding: Localized functions of cytosolic chaperones. Trends Biochem Sci 28: 541-547.

Yuan, Q., Duan, H.-H., Li, L.-L., Sun, , L.-D., Z., Y.-W. \& Yan, C.-H. 2009. Controlled synthesis and assembly of ceria-based nanomaterials. J. Colloid Interface Sci. 335: 151-167.

Zeyons, O., Thill, A., Chauvat, F., Menguy, N., Cassier-Chauvat, C., Orear, C., Daraspe, J., Auffan, M., Rose, J. \& Spalla, O. 2009. Direct and indirect $\mathrm{CeO}_{2}$ nanoparticles toxicity for Escherichia coli and Synechocystis. Nanotoxicology 3: 284-295.

Zhou, X., Wong, L. L., Karakoti, A. S., Seal, S. \& McGinnis, J. F. 2011. Nanoceria inhibit the development and promote the regression of pathologic retinal neovascularization in the Vldlr knockout mouse. PLoS ONE 6: e16733. 


\section{Figure legends}

Figure 1 Nanoceria imaged using high-resolution-TEM. The ceria were dispersed on a carbon film.

Figure 2 Schematic illustration for $30 \mathrm{~nm} \mathrm{CeO} 2$ particle cross section: areas of enriched Ce III correspond to $\mathrm{CeO}_{2-x}$ (oxygen vacancies in surface layer). EELS analyses (performed with nanoprobe $\sim 1 \mathrm{~nm}$ ) show oxidation state variations for the surface and the bulk. Bulk ceria show $\mathrm{Ce} \mathrm{M}_{5} / \mathrm{M}_{4}$ peaks with $\mathrm{M}_{5}<\mathrm{M}_{4}\left(\mathrm{M}_{4}\right.$ line stronger than $\left.\mathrm{M}_{5}\right)$ and typical Ce IV features identified as satellite peaks (dashed circles). Surface layer shows weaker $\mathrm{M}_{4}$ line $\left(\mathrm{M}_{5}>\mathrm{M}_{4}\right.$, i.e., $\mathrm{Ce}$ III $>\mathrm{Ce}$ IV) and no satellite peaks.

Figure 3 GPx and Cat levels-(a) and activities-(b) bottom in rat hippocampus after $30 \mathrm{~nm}$ nanoceria infusion.

Figure 4 PC and 3NT levels in rat hippocampus after $30 \mathrm{~nm}$ nanoceria infusion.

Figure 5 HO-1 and Hsp70 protein levels in rat hippocampus after $30 \mathrm{~nm}$ nanoceria infusion.

Figure 6 IL-1 $\beta$ and TNF- $\alpha$ levels in rat hippocampus after $30 \mathrm{~nm}$ nanoceria infusion.

Figure 7 Pro-caspase-3levels in rat hippocampus after $30 \mathrm{~nm}$ nanoceria infusion.

Figure $8 \mathrm{LC}-3 \mathrm{AB}$ levels in rat hippocampus after $30 \mathrm{~nm}$ nanoceria infusion.

Figure 9 This figure summarizes the findings of the current study and their correlation with the HOS model with extension (Tier 4) based on rat hippocampal oxidative stress responses observed from $1 \mathrm{~h}$ to $90 \mathrm{~d}$ after a single systemic infusion of $30 \mathrm{~nm}$ ceria ENM. Fig. 9a) Tabular 
representation of quantitative changes in oxidative stress parameters as a function of time, Fig. 9b) schematic representation of mechanisms of nanoceria-induced oxidative stress and toxicity as a function of changes in oxidative stress markers (Note: the $\mathrm{x}$-axis in this figure is not drawn to scale). A single infusion of $30 \mathrm{~nm}$ nanoceria increased the GSSG: GSH ratio, which induced a Tier-1 response during 1-20 h, leading to elevation of phase-II antioxidant enzymes GPx and Cat levels and activities through activation of the Nrf-2 signaling pathway. The biopersistent nanoceria-induced oxidative stress maintained elevated levels of the GSSG: GSH ratio after $1 \mathrm{~d}$, GPx and Cat activities were inhibited and PC, 3NT, HO-1, and Hsp70 levels were elevated. Consequently, the HOS model Tier 2 response was evoked by activation of NF-кB pathways leading to induction of inflammatory cytokine IL-1 $\beta$ levels at $1 \mathrm{~d}$. As oxidative stress persisted the major impact on cellular homeostasis was observed at $30 \mathrm{~d}$. The Tier-3 response was activated, indicated by augmentation in IL-1 $\beta$ and pro-apoptotic pro-caspase- 3 levels observed $30 \mathrm{~d}$ after ceria treatment. The progression of oxidative stress was reversed as the GSSG: GSH ratio, GPx activity, and HO-1, Hsp70, IL-1 $\beta$, and pro-caspase-3 levels returned to normalcy at $90 \mathrm{~d}$. In order to better understand the return to normalcy of the oxidative stress response, the levels of the autophagy marker LC-3AB were measured. LC-3AB levels showed an increase 7 and $30 \mathrm{~d}$ after nanoceria infusion along with an increasing trend in Hsp70 levels. Concomitant changes in LC-3AB and Hsp70 suggest the possibility of activation of a chaperone mediatedautophagy process, which conceivably may have helped in restoration of redox balance at $90 \mathrm{~d}$ and cellular adaptation to $30 \mathrm{~nm}$ nanoceria mediated-oxidative stress injury. Therefore, mitigation of the oxidative stress response observed at $90 \mathrm{~d}$ is proposed as Tier 4 , an extension to the HOS three-tiered model. 


\section{Table and Figures}

Table 1 Cerium in blood, brain, and liver, expressed as a percent of the nanoceria dose ${ }^{\mathrm{a}}$

\begin{tabular}{|c|c|c|c|}
\hline & Blood & Brain & Liver \\
\hline $\mathbf{1 ~ h}$ & $0.01 \pm 0.01$ & $0.0003 \pm 0.0002$ & $40 \pm 7$ \\
\hline $\mathbf{2 0 - 2 4} \mathbf{~}$ & $0.20 \pm 0.11$ & $0.018 \pm 0.016$ & $33 \pm 9$ \\
\hline $\mathbf{7 ~ d}$ & $0.0043 \pm 0.0002$ & $0.00035 \pm 0.00002$ & $37 \pm 7$ \\
\hline $\mathbf{3 0 ~ d}$ & $0.0046 \pm 0.0047$ & $0.00064 \pm 0.00066$ & $30 \pm 11$ \\
\hline $\mathbf{9 0 ~ d}$ & $3.81 \pm 2.67$ & $0.001 \pm 0.001$ & $21 \pm 8$ \\
\hline
\end{tabular}

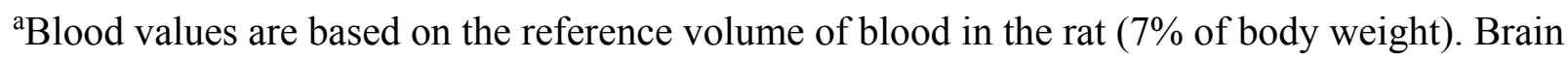
and liver values were calculated from the ceria concentration $\mathrm{x}$ organ weight/nanoceria dose. 
Figure 1

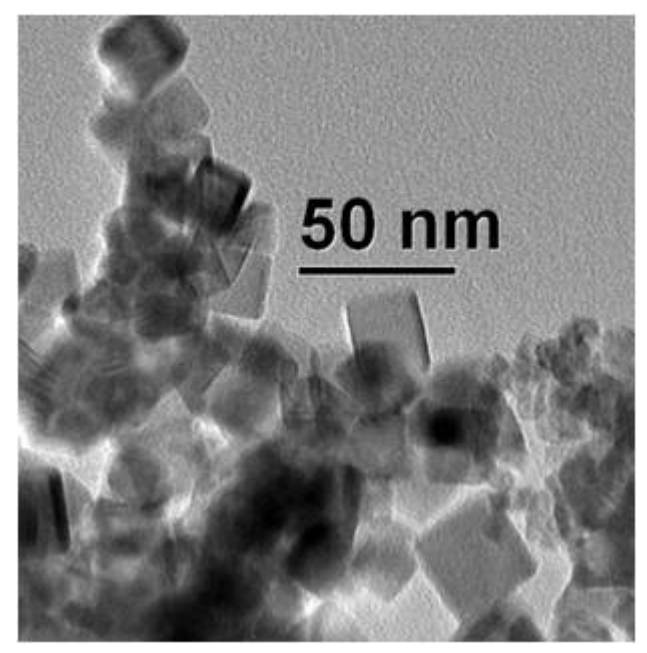


Figure 2

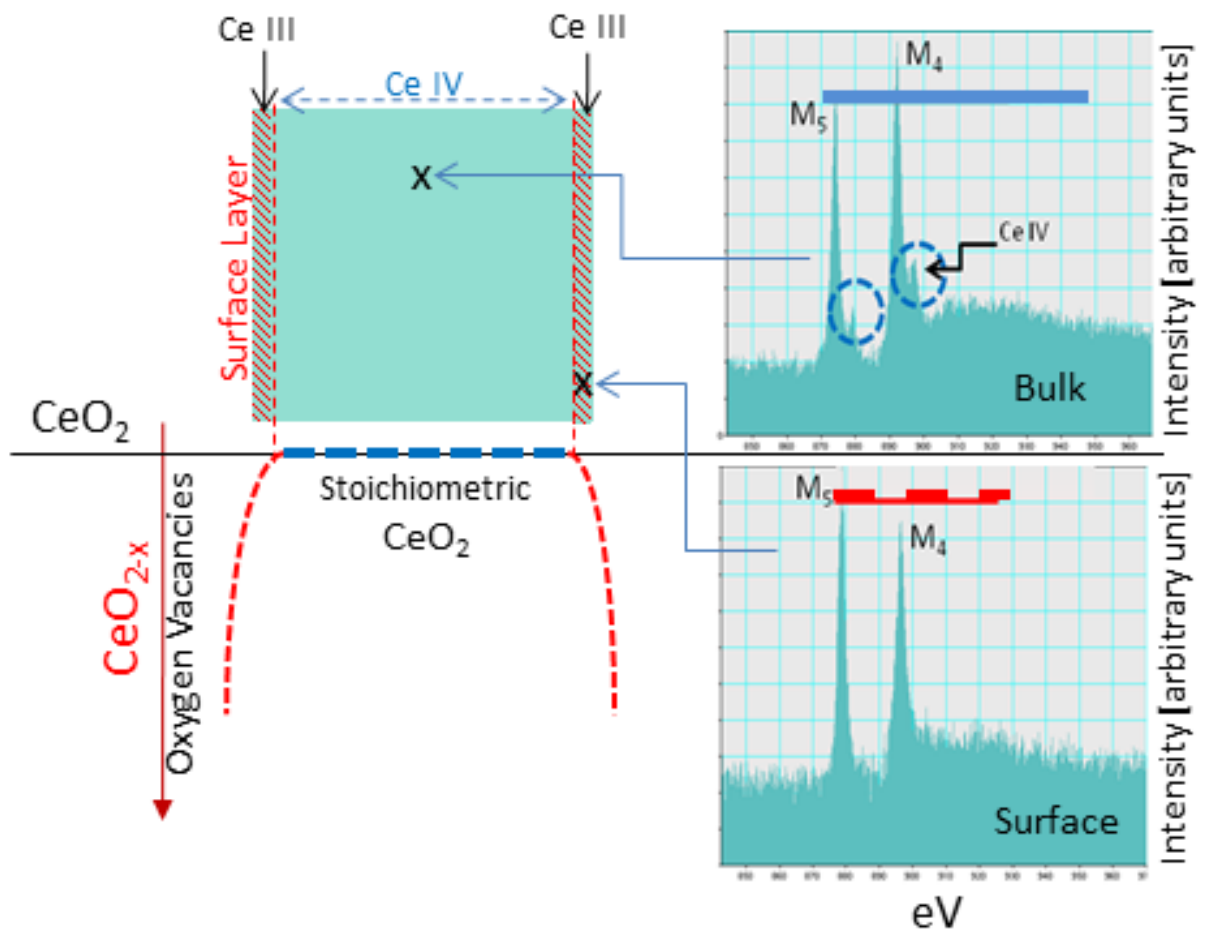


Figure $3 a$ and $b$
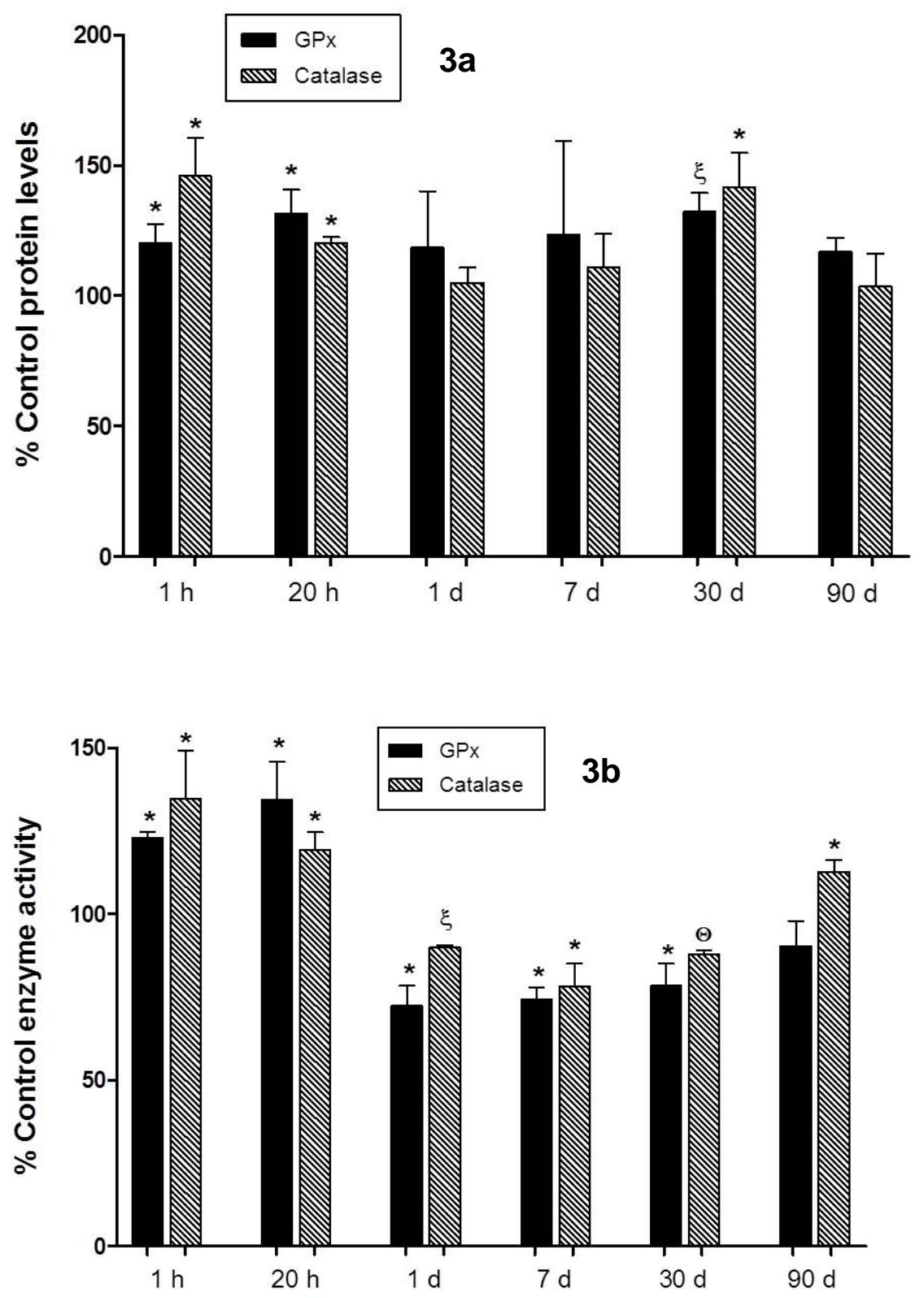
Figure 4

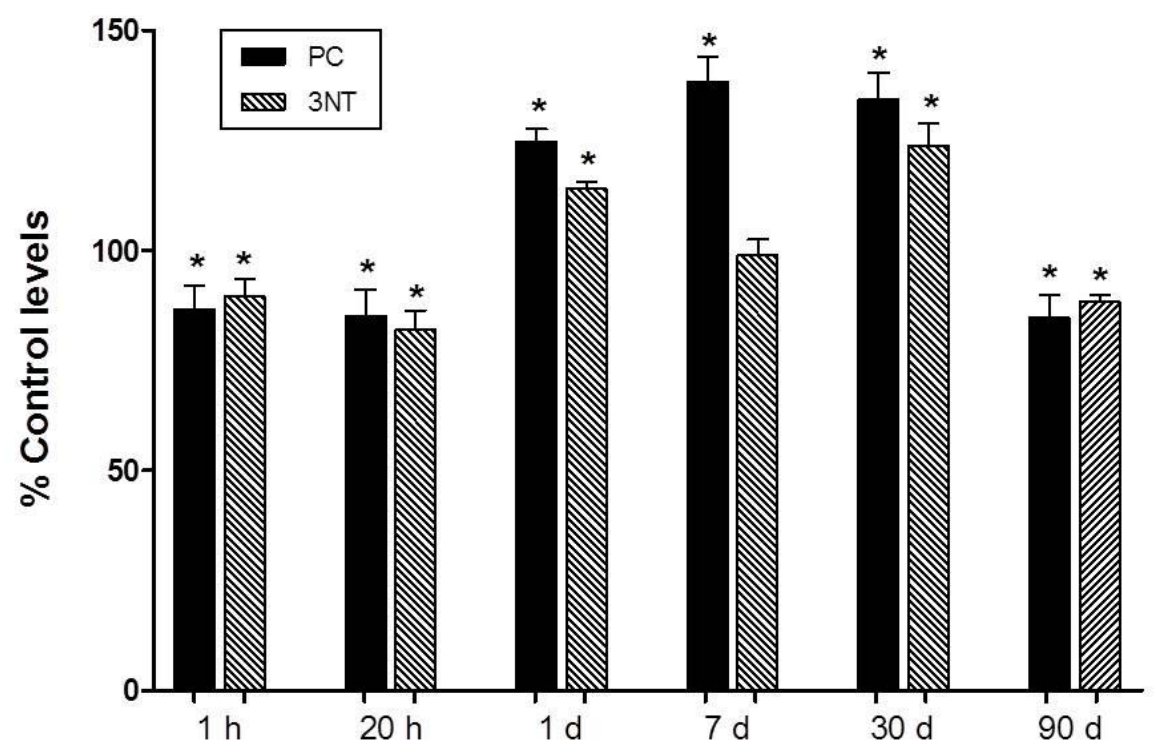


Figure 5

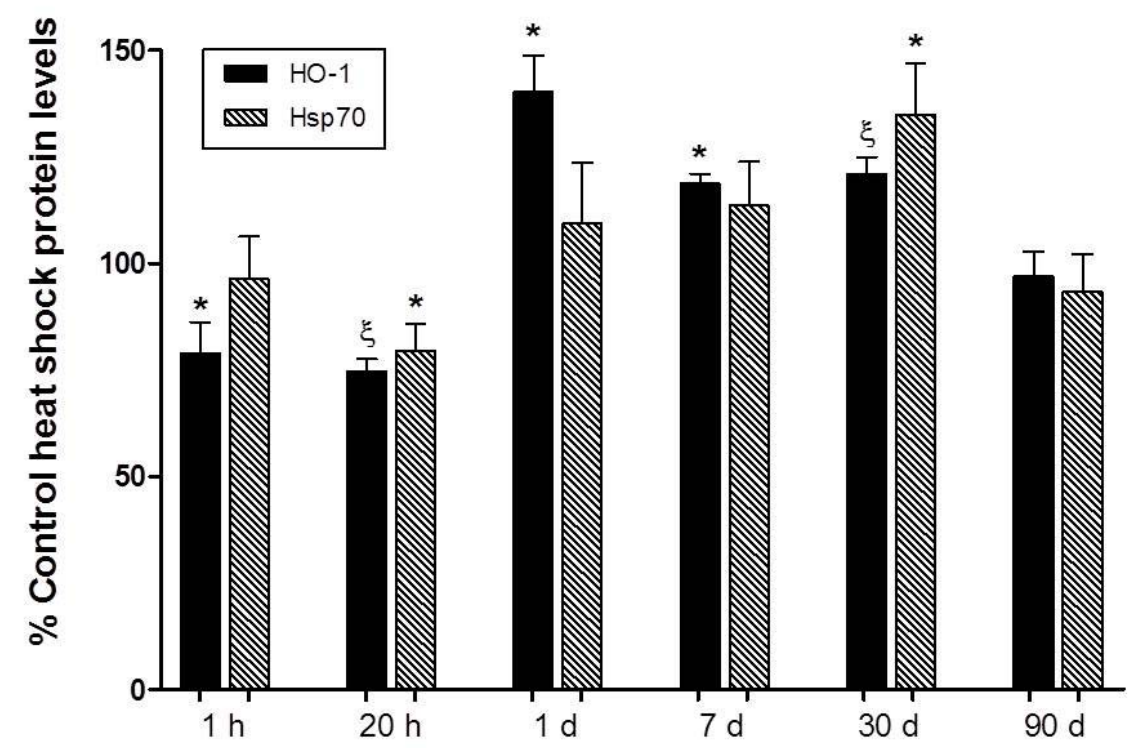


Figure 6

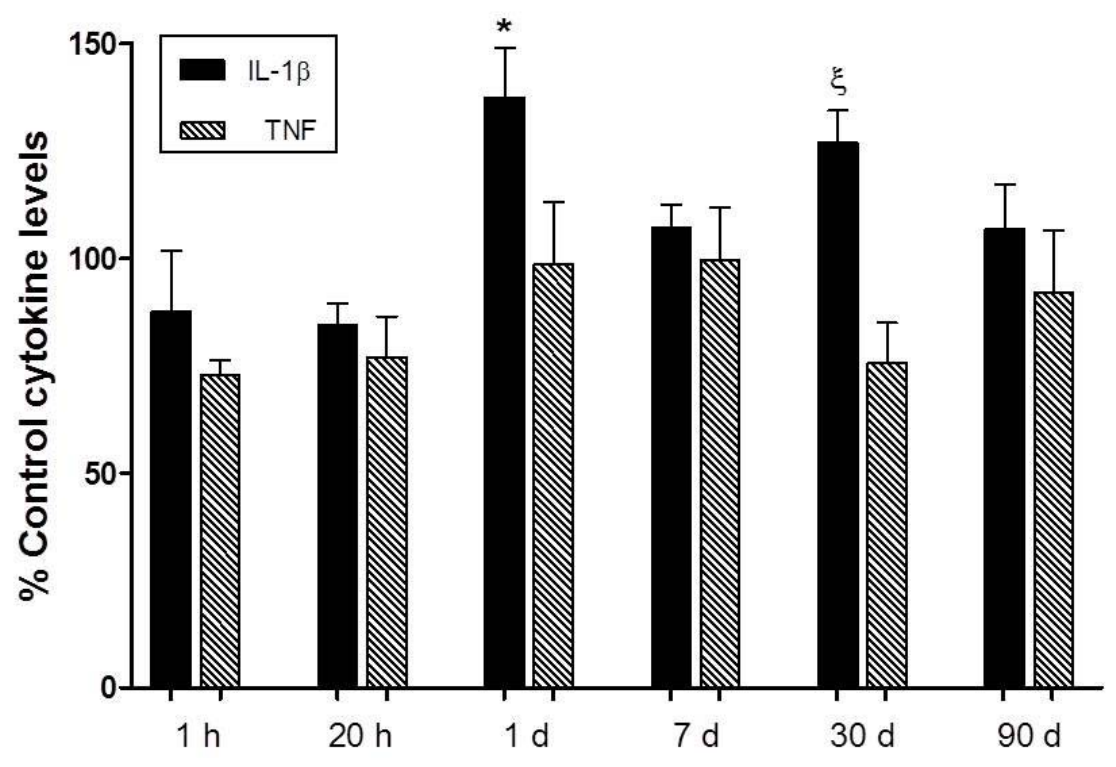


Figure 7

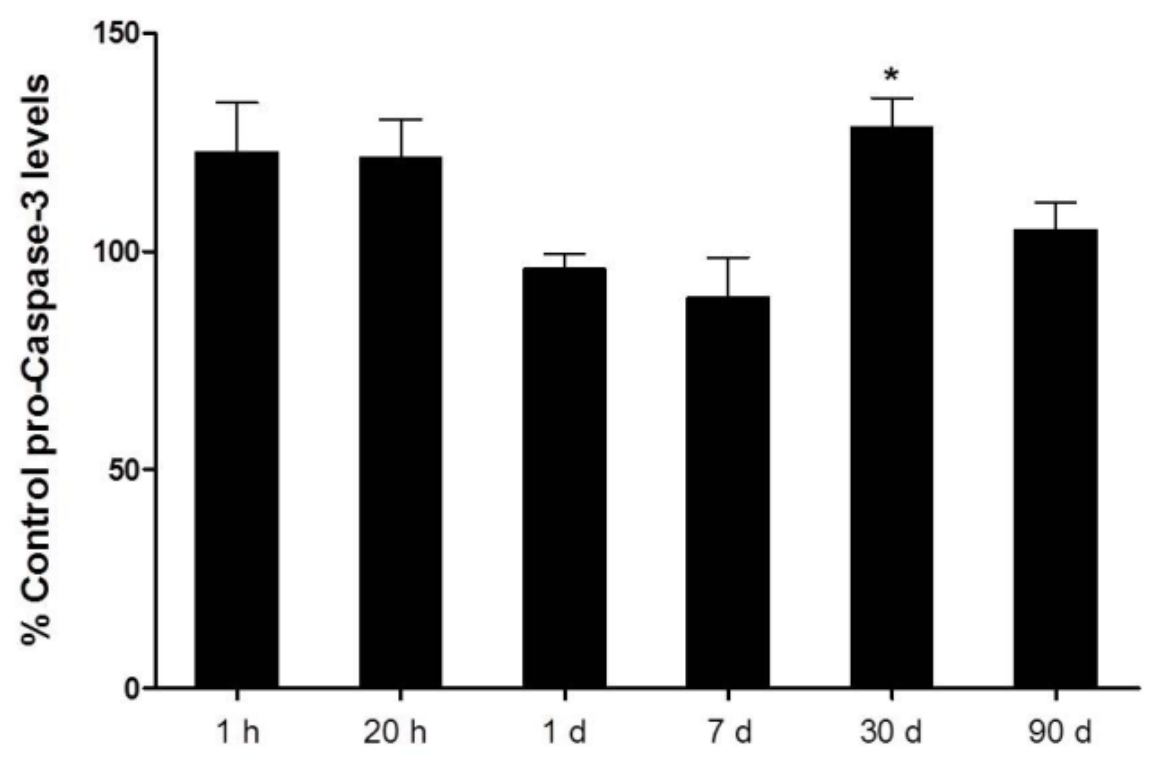


Figure 8

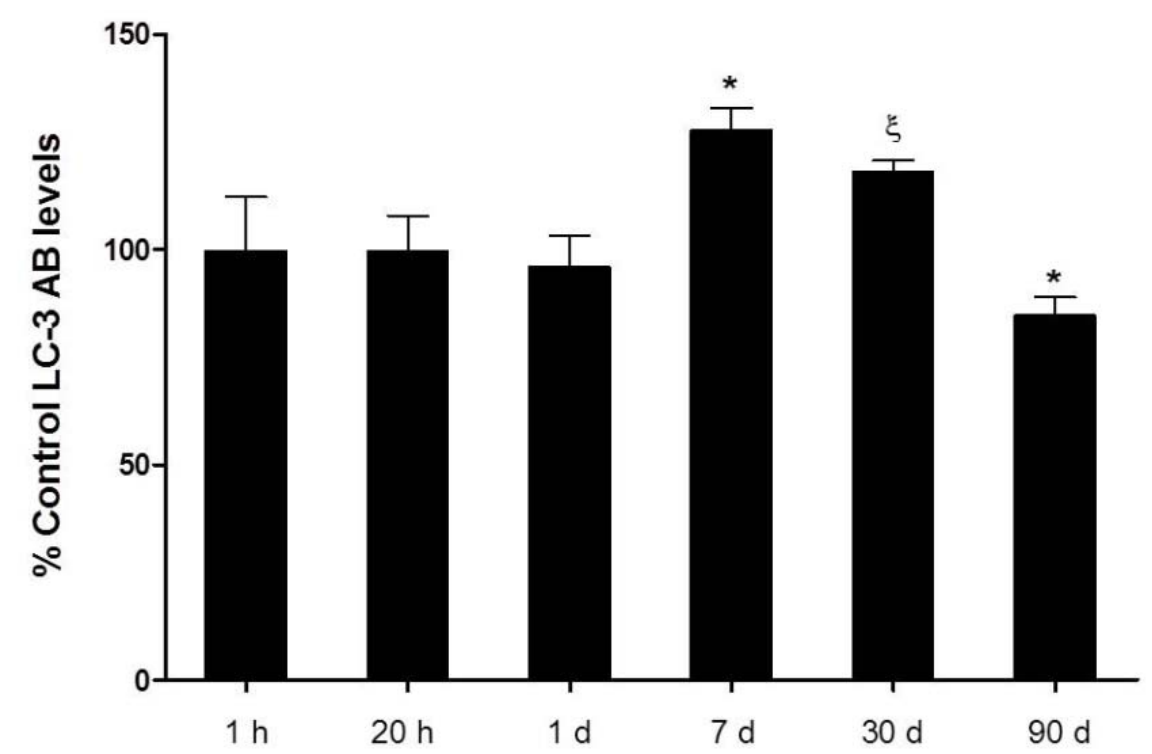




\section{Figure 9a and b}

\begin{tabular}{|c|c|c|c|c|c|c|}
\hline $\begin{array}{l}\text { Ox stress } \\
\text { parameter }\end{array}$ & $1 \mathrm{~h}$ & $20 \mathrm{~h}$ & $1 \mathrm{~d}$ & $7 \mathrm{~d}$ & $30 \mathrm{~d}$ & $90 \mathrm{~d}$ \\
\hline \multicolumn{7}{|l|}{ GSSG: GSH } \\
\hline \multicolumn{7}{|l|}{ GPx levels } \\
\hline \multicolumn{7}{|l|}{ GPx activity } \\
\hline \multicolumn{7}{|l|}{ Cat levels } \\
\hline \multicolumn{7}{|l|}{ Cat activity } \\
\hline \multicolumn{7}{|l|}{ PC } \\
\hline \multicolumn{7}{|l|}{$3 N T$} \\
\hline \multicolumn{7}{|l|}{ HO-1 } \\
\hline \multicolumn{7}{|l|}{ Hsp70 } \\
\hline \multicolumn{7}{|l|}{ IL-1Beta } \\
\hline \multicolumn{7}{|l|}{ pro-caspase-3 } \\
\hline \multicolumn{7}{|l|}{ LC-3AB } \\
\hline HOS model & & & Tie & & Tier-3 & Tier-4 \\
\hline
\end{tabular}

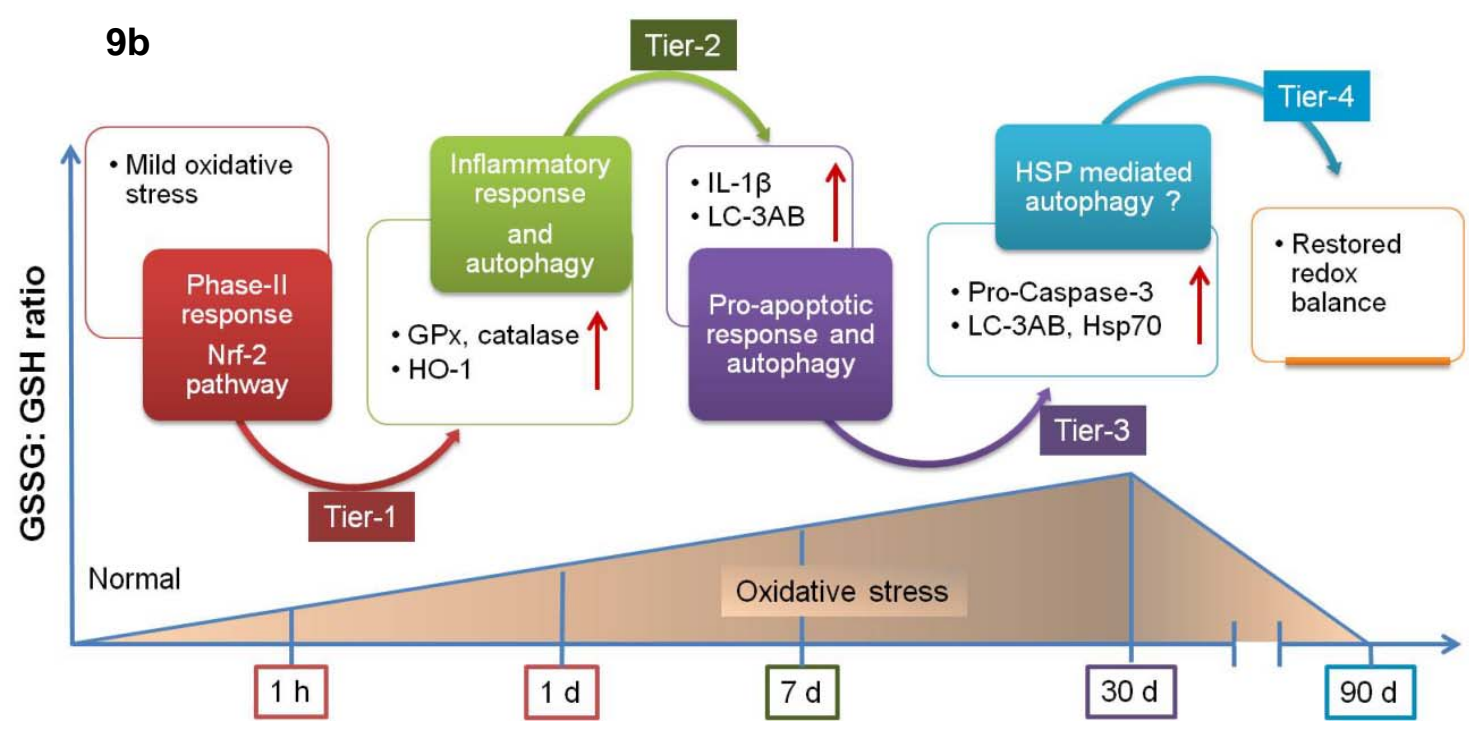

